\title{
Assimilating GlobColour ocean colour data into a pre-operational physical-biogeochemical model
}

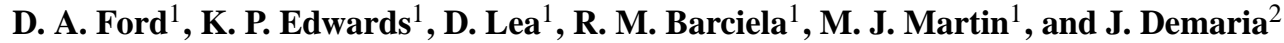 \\ ${ }^{1}$ Met Office, FitzRoy Road, Exeter, EX1 3PB, UK \\ ${ }^{2}$ ACRI-ST, 260 Route du Pin Montard, BP 234, 06904 Sophia Antipolis Cedex, France
}

Correspondence to: D. A. Ford (david.ford@metoffice.gov.uk)

Received: 13 January 2012 - Published in Ocean Sci. Discuss.: 17 February 2012

Revised: 5 July 2012 - Accepted: 23 July 2012 - Published: 5 September 2012

\begin{abstract}
As part of the GlobColour project, daily chlorophyll $a$ observations, derived using remotely sensed ocean colour data from the MERIS, MODIS and SeaWiFS sensors, are produced. The ability of these products to be assimilated into a pre-operational global coupled physicalbiogeochemical model has been tested, on both a hindcast and near-real-time basis, and the impact on the system assessed. The assimilation was found to immediately and considerably improve the bias, root mean square error and correlation of modelled surface chlorophyll concentration compared to the GlobColour observations, an improvement which was sustained throughout the year and in every ocean basin. Errors against independent in situ chlorophyll observations were also reduced, both at and beneath the ocean surface. However, the model fit to in situ observations was not consistently better than that of climatology, due to errors in the underlying model. The assimilation scheme used is multivariate, updating all biogeochemical model state variables at all depths. The other variables were not degraded by the assimilation, with annual mean surface fields of nutrients, alkalinity and carbon variables remaining of similar quality compared to climatology. There was evidence of improved representation of zooplankton concentration, and reduced errors were seen against in situ observations of nitrate and $p \mathrm{CO}_{2}$, but too few observations were available to conclude about global model skill. The near-real-time GlobColour products were found to be sufficiently reliable for operational purposes, and of benefit to both operational-style systems and reanalyses.
\end{abstract}

\section{Introduction}

Operational marine biogeochemical models are required for a variety of purposes (Brasseur et al., 2009; Berx et al., 2011). These include monitoring air-sea carbon fluxes and plankton levels in a changing climate, forecasting algal blooms which may be harmful to human health or to fisheries, providing information about the marine environment to fisheries managers and policy makers, and predicting the ocean state for naval customers. In this context, "operational" is used to describe an automated system which runs in realtime or near-real-time (NRT), and delivers products to end users.

There is also the need for reanalyses, as these provide high quality data sets that are also methodologically consistent. Biogeochemical reanalyses are key to reconstruct past conditions in the ocean, understand and differentiate natural variability and climate trends, improve the biases in models and observations, and provide information for present and future monitoring programmes.

In general, the most realistic representation of the ocean's biogeochemistry is required. Data assimilation, which is widely used in numerical weather prediction (NWP; Kalnay, 2003) and operational physical oceanography (Cummings et al., 2009), can help with this aim by combining the advantages of models and observations. Models give full spatial and temporal coverage of the ocean, but contain errors resulting from inadequate approximations, parameterisations, forcings and initial conditions. Observations are typically more accurate, but are sparse and still contain sources of error. Combining the two can produce results which have full spatial and temporal coverage, that can be used for 
forecasting, and which are potentially more accurate than either models or observations alone (Gregg et al., 2009; Cummings et al., 2009).

Data assimilation can be used either for parameter estimation or for state (or flux) estimation. In marine biogeochemistry, much of the focus to date has been on parameter estimation, usually with a zero-dimensional (0-D) or onedimensional (1-D) model (e.g. Matear, 1995; Hemmings et al., 2004). This technique adjusts the internal parameters of a model such that a subsequent model simulation will match the observations as closely as possible. It is typically performed as a tuning exercise, to decide the best values for parameters whose real-world values are unknown.

In this study data assimilation is used for state estimation, employing a sequential (Talagrand, 1997) technique. This technique adjusts a model field based on observations in order to produce an analysis, which is the best estimate of the ocean state at a given time. The process is stepped through time to provide a series of analyses, each of which can then act as the initial conditions for a forecast. The majority of applications of marine biogeochemical data assimilation for state estimation have involved assimilating real or simulated chlorophyll observations. These have been used to update phytoplankton fields, typically in a univariate manner. An overview of some of these efforts, with a focus on skill assessment, is given in Gregg et al. (2009). Many of these have used 0-D models (e.g. Losa et al., 2003), or 1-D models (e.g. Eknes and Evensen, 2002; Allen et al., 2003; Hoteit et al., 2003; Torres et al., 2006; Raick et al., 2007). Hemmings et al. (2008) tested the assimilation scheme used in the present study in a 1-D test bed in the North Atlantic. This test used simulated chlorophyll and phytoplankton observations to directly update the model phytoplankton, zooplankton, nutrient, detritus, dissolved inorganic carbon (DIC) and alkalinity fields. The increments to each variable were calculated using a principle of total nitrogen and carbon conservation. The assimilation was found to be of overall benefit to both the nitrogen and carbon variables, and produced more realistic fields than if just the model phytoplankton was updated. In this study the scheme has been extended to directly update all biogeochemical state variables in a three-dimensional (3D) model based on remotely sensed surface chlorophyll observations.

A number of studies have assimilated biogeochemical data into 3-D regional models (e.g. Ishizaka, 1990; Anderson et al., 2000; Carmillet et al., 2001; Popava et al., 2002; Beşiktepe et al., 2003; Triantafyllou et al., 2003; Hoteit et al., 2005; Fontana et al., 2010). Natvik and Evensen (2003) assimilated remotely sensed chlorophyll data into a model of the North Atlantic. With respect to a control run, this resulted in a qualitative improvement in surface phytoplankton compared to the satellite data, and consistent changes in subsurface phytoplankton, zooplankton and nitrate. Ourmières et al. (2009) assimilated nitrate climatology values into a model of the North Atlantic, which improved the model's representation of nitrate compared to the climatology, and led to an improved representation of chlorophyll compared to satellite data. Ciavatta et al. (2011) assimilated chlorophyll data into a model of the western English Channel. This resulted in improvements compared to the assimilated data, and also an improved representation of other biogeochemical variables, including a number of plankton functional types and nutrients, compared to independent in situ observations.

Few studies have assimilated biogeochemical data into a global model. Nerger and Gregg (2007) assimilated chlorophyll data into the NASA Ocean Biogeochemical Model (NOBM), resulting in significantly improved globally averaged modelled surface chlorophyll when compared to both assimilated and independent observations. Primary production was also improved when compared to satellite data, however surface nitrate was slightly degraded compared to a climatology. Nerger and Gregg (2008) extended the work to include an online model bias correction scheme, which further improved model surface chlorophyll concentrations. Gregg (2008) also assimilated chlorophyll into NOBM, using a different method. The assimilation improved surface chlorophyll compared to the assimilated data on daily, monthly and annual timescales, at both regional and global scales, and also when compared to independent data. Simulations were found to improve with assimilation frequency. Primary production was also improved, but not by as much as expected, with Gregg (2008) suggesting a need for multivariate assimilation. While et al. (2012) assimilated in situ observations of the partial pressure of carbon dioxide $\left(p \mathrm{CO}_{2}\right)$ into the model used in this study, resulting in a significant reduction in model $p \mathrm{CO}_{2}$ bias and root mean square error in comparison to the assimilated observations. The assimilation was found to have a long memory, with observations positively influencing results several months after assimilation.

Coupled physical-biogeochemical models are increasingly being run operationally, as well as for research purposes. For instance, as of January 2012, there are six on-line or off-line coupled physical-biogeochemical models regularly providing products to the MyOcean project (http://www.myocean. eu). Two of these assimilate biogeochemical data; the model for the Mediterannean Sea (Teruzzi et al., 2011) and the model for the Arctic Ocean (Samuelsen and Bertino, 2011; Simon and Bertino, 2012). A discussion of progress and challenges in developing operational biogeochemical models with data assimilation is given in Brasseur et al. (2009), whilst a pre-operational coupled physical-biogeochemical model has been run daily with biogeochemical data assimilation since 2009, as part of this current study.

For observations to be assimilated operationally they must be available in NRT (Le Traon et al., 2009), as this allows models to run on a regular basis in a robust and reliable manner. Using data which describe the current ocean state gives maximum benefit, as the model can be effectively and realistically constrained by the data assimilation. This operational requirement is addressed by the GlobColour project (Fanton 
d'Andon et al., 2008), which provides a long time series of calibrated and validated satellite ocean colour observations for the global ocean, as well as a set of NRT products which are updated daily. Surface chlorophyll concentrations are derived from these, and it is this data set which is assimilated in this study.

The study presented in this paper has two aims. The first is to test whether the GlobColour observations can be assimilated reliably into a global coupled physical-biogeochemical model running on an operational basis. This includes assessing the suitability, robustness and timeliness of the data and their delivery. The second aim is to test the impact of the assimilation on the model's representation of chlorophyll concentration, the carbon cycle and other biogeochemical variables of interest.

The physical-biogeochemical model, observations and biological data assimilation scheme used in this study are described in Sects. 2, 3 and 4, respectively. Experiments to test the effectiveness of the data assimilation are described in Sect. 5, and the results presented in Sect. 6. Conclusions are drawn and the pre-operational running of the system discussed in Sect. 7.

\section{Model description}

This study uses a coupled physical-biogeochemical model, the physical component of which is the Forecasting Ocean Assimilation Model (FOAM). Details of the FOAM system and its performance are not given here, but are described in Storkey et al. (2010). The version used in this study is based on version 3.2 of the Nucleus for European Modelling of the Ocean (NEMO) hydrodynamic model (Madec, 2008), and the second version of the Louvain-le-Neuve sea ice model (LIM2; Timmermann et al., 2005). At the surface the model is forced by six-hourly mean fluxes from the Met Office global NWP model. A key feature of FOAM is the ability to assimilate remotely sensed and in situ observations of temperature, salinity, sea-level anomaly (SLA) and sea ice concentration. The data assimilation scheme is of optimal interpolation (OI)-type, and is described in detail in Martin et al. (2007) and Storkey et al. (2010). The FOAM system is run operationally at the Met Office on a daily basis, producing analyses and six-day forecasts. It is run globally at $1 / 4^{\circ}$ resolution, and in three $1 / 12^{\circ}$ regional configurations, covering the North Atlantic Ocean, Indian Ocean and Mediterranean Sea. However, due to the additional computational cost of the biogeochemical model, for the purposes of this study a nonoperational version of the FOAM system is being run globally, using a $1^{\circ}$ tripolar grid with 42 vertical levels, although still including physical data assimilation.

The biogeochemical component of the coupled model is the Hadley Centre Ocean Carbon Cycle Model (HadOCC; Palmer and Totterdell, 2001). HadOCC is a relatively simple nutrient, phytoplankton, zooplankton and detritus (NPZD) model, which also includes dissolved inorganic carbon (DIC) and alkalinity to complete the carbon cycle. The main nutrient component in HadOCC is nitrate (ammonium is also derived), so the NPZD variables are modelled in terms of their nitrogen content. Conversion between carbon and nitrogen is performed using fixed ratios, and a list of parameters used within HadOCC is provided in Table A1. HadOCC has been widely used for carbon cycle studies at the Met Office Hadley Centre, and was the ocean biogeochemical component of the first coupled climate-carbon model (Cox et al., 2000), which examined future climate-carbon feedbacks. A development of the model, Diat-HadOCC (Totterdell and Halloran, 2012), which has a more complex ecosystem, has recently been used in simulations that will form part of the Intergovernmental Panel on Climate Change (IPCC) 5th Assessment Report.

HadOCC is shown schematically in Fig. 1, and the model equations are given in Hemmings et al. (2008). The state variables are all treated as oceanic tracers, and are advected using the Monotonic Upstream Scheme for Conservation Laws (MUSCL) scheme, which forms part of the NEMO code (Lévy et al., 2001). Chlorophyll, which is assimilated in this study, is not a state variable within the model, but is derived from phytoplankton using nitrogen to carbon and carbon to chlorophyll ratios. DIC and alkalinity are controlled by the physical and NPZD variables, but have no influence on them. Their inclusion allows the calculation of sea surface $p \mathrm{CO}_{2}$ and air-sea $\mathrm{CO}_{2}$ flux, which are in turn affected by atmospheric $p \mathrm{CO}_{2}$. This is assumed to be spatially constant, with a value of $389.30 \mathrm{ppm}$ used for 2008 .

Since Palmer and Totterdell (2001), the light penetration model of Anderson (1993) has been implemented in HadOCC. Furthermore, a variable phytoplankton carbon to chlorophyll ratio has been added, which is allowed to vary between 20 and 200. The method used for the carbon to chlorophyll ratio is that of Geider et al. (1996), with nutrient and temperature effects implemented as suggested by Geider et al. (1997). Using a variable ratio has been found to give a more realistic conversion between phytoplankton biomass and chlorophyll concentration. HadOCC also has the option to allow phytoplankton growth rates to increase with temperature through use of a $Q_{10}$ parameter (Eppley, 1972; Palmer and Totterdell, 2001), an option which is utilised in this study.

HadOCC is coupled on-line to NEMO, and is called at every model time step $(30 \mathrm{~min})$. The coupling is one-way, which means that the physical fields drive the biogeochemical variables, but there is no feedback from the biogeochemical to the physical variables.

\section{GlobColour data}

A detailed description of the GlobColour products is given in the GlobColour Product User Guide (http://www. globcolour.info/CDR_Docs/GlobCOLOUR_PUG.pdf,

25 January 2011), and they can be accessed via 


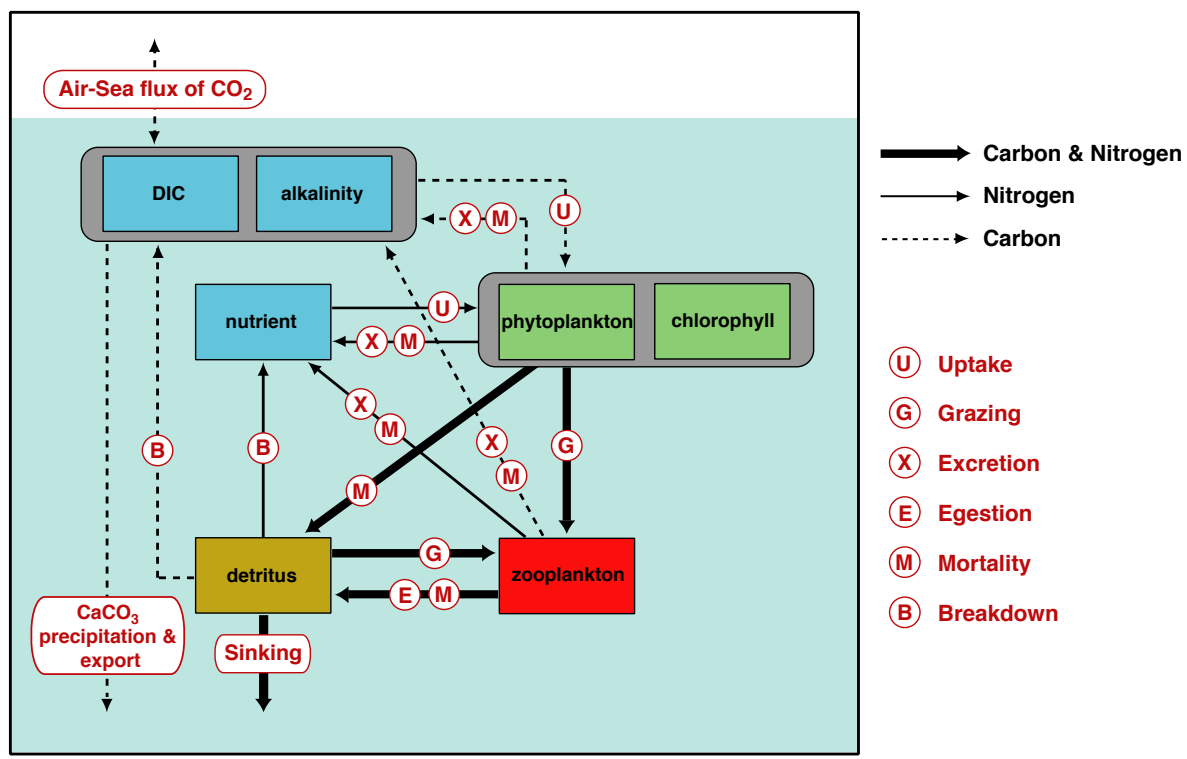

Fig. 1. Schematic of the HadOCC model.

http://www.globcolour.info or http://www.myocean.eu. The data assimilated in this study are global chlorophyll products derived using remotely sensed ocean colour observations from three different sensors. These are the Medium Resolution Imaging Spectrometer (MERIS) on board the Envisat satellite; the Moderate Resolution Imaging Spectroradiometer (MODIS) on board Aqua; and the Sea-viewing Wide Field-of-view Sensor (SeaWiFS) on board SeaStar. Information from the MODIS sensor on board Terra is not used, and all references to MODIS in this paper refer to MODIS-Aqua.

GlobColour offer an archive of merged daily average level three (Blower et al., 2009) chlorophyll products dating back to the launch of SeaWiFS in 1997, which are freely available and described in Sect. 3.1. NRT products are available a day behind real-time, and will be discussed further in Sect. 7 . The GlobColour products are generated from level two radiance data provided by the European Space Agency (ESA) for MERIS, and the National Aeronautics and Space Administration (NASA) for MODIS and SeaWiFS. The products assimilated in this study are based on the MERIS 2nd reprocessing (2006), and MODIS 1.1 and SeaWiFS 5.2 reprocessings. However, more recent reprocessings are now available (MERIS 3rd, MODIS R2009.1 and R2010.0, and SeaWiFS R2010.0), and current NRT GlobColour products make use of these. Furthermore, the full GlobColour archive will be reprocessed during 2012, and the impact this might have is discussed in Sect. 3.2.

\subsection{Level three merged products}

The products used in this study are daily averaged fields of sea surface chlorophyll. These are gridded at a resolution of
$1 / 24^{\circ}$ (4.63 $\mathrm{km}$ at the equator), on an integerised sinusoidal (ISIN) grid. There is global coverage, although there are no data at high latitudes for the winter Hemisphere, and there are also gaps where there is cloud. On average the products cover $25.22 \%$ of the ocean each day, and $87.69 \%$ of the ocean each month (Maritorena et al., 2010), although this has decreased with more recent SeaWiFS reprocessings. The coverage is considerably greater than is achieved by in situ observations, but satellites have the disadvantage of being unable to take measurements beneath the ocean's surface.

Chlorophyll is generated from the water-leaving radiances using the Garver, Siegel, Maritorena (GSM) model, as described in Maritorena et al. (2010), and data from the three sensors are merged and gridded at this stage. During 2008 some problems were experienced with the SeaWiFS sensor, which was later decommissioned in December 2010, resulting in periods of data being lost or deemed unreliable. Therefore not all days in 2008 contain a contribution from SeaWiFS.

For the purposes of daily averaging, a so-called "data-day" is defined. This means that some observations valid at around 00:00 UTC count towards the day before or after the day they were observed. This is to avoid combining observations made at the same point at significantly different times of day. The day an observation counts towards depends on the observation time and longitude, and the satellite's orbit. Whilst the products are daily averages, it should be noted that the three satellites are helio-synchronous, and all observations are made within two hours of local noon.

For each observation there is an error estimate and a set of confidence flags. The error estimates are generated by the GSM model, and the confidence flags mark whether an 
observation is, for instance, contaminated by cloud or land. The way these flags are used in this study is detailed in Sect. 4. The products are only accurate for clear case one (Morel and Prieur, 1977) waters, as the GSM algorithm is not designed to account for the increased amount of suspended matter present in case two waters.

\subsection{Product accuracy}

The SeaWiFS pre-launch accuracy target for chlorophyll was $35 \%$ over the range $0.05-50.0 \mathrm{mg} \mathrm{m}^{-3}$ (Hooker et al., 1992). This is the figure often quoted for the accuracy of satellite chlorophyll products. The target for the waterleaving radiances was $5 \%$ (Hooker et al., 1992). Bailey and Werdell (2006) conducted a comprehensive validation of SeaWiFS data against in situ measurements of radiances and surface chlorophyll. For chlorophyll derived using the OC4 algorithm (O'Reilly et al., 1998), they found the median percentage error compared to all available in situ measurements to be $33.09 \%$, reducing to $25.96 \%$ when comparing to observations taken in the open ocean (bottom depth greater than $1000 \mathrm{~m}$ ).

The GlobColour Full Validation Report (http://www. globcolour.info/validation/report/GlobCOLOUR_FVR_v1.1. pdf, version 1.1, 14 December 2007) provides similar validation for the merged GlobColour products. This validation compares the products to in situ data, to the operational products of the three individual sensors, and to other merged products. The median percentage error for the merged GlobColour GSM chlorophyll product when compared to in situ measurements taken in the open ocean was found to be $29.53 \%$. For the operational MERIS, MODIS and SeaWiFS products this figure was $53.04 \%, 44.08 \%$ and $35.77 \%$, respectively. This demonstrates the advantage of using the merged product (along with increased coverage and consistency).

An issue with the merged GlobColour data set is that there are known biases between the sensors. Using NASA products, Gregg and Casey (2010) found a $12.2 \%$ difference between MODIS and SeaWiFS global annual median chlorophyll concentrations over the period 2003-2007. Using GlobColour products, Maritorena et al. (2010) found that since 2005, chlorophyll values derived from MERIS and SeaWiFS have remained fairly steady, but values from MODIS have decreased markedly. There was a reduction of $16 \%$ between the periods 2002-2005 and 2006-2009. This is evident in the GlobColour products used in this study. By comparing the merged product and the equivalent individual sensor products, it was found that after the quality control procedure described in Sect. 4 had been performed, the mean daily global chlorophyll concentrations for 2008 were $0.211 \mathrm{mg} \mathrm{m}^{-3}$ from the merged product, $0.270 \mathrm{mg} \mathrm{m}^{-3}$ from MERIS, $0.185 \mathrm{mg} \mathrm{m}^{-3}$ from MODIS and $0.227 \mathrm{mg} \mathrm{m}^{-3}$ from SeaWiFS. SeaWiFS values are typically closer to those from MERIS than to those from MODIS, which means that when SeaWiFS data are available, the average chlorophyll concentration from the three sensors, and so in the merged product, increases, even though chlorophyll levels in the ocean have not significantly changed.

These biases should be reduced in future versions of the GlobColour archive, by making use of the most recent ESA and NASA reprocessings. In the products used in this study it can often be clearly seen where different satellite tracks, with contrasting chlorophyll concentrations, cross over. An example of this is shown in Fig. 2. This effect is considerably reduced in the equivalent product generated using the most recent reprocessings. The impact of these biases could also be addressed by assimilating the individual sensor products, and developing a bias correction scheme such as that used within FOAM for sea surface temperature (Martin et al., 2007).

\section{Biological assimilation}

\subsection{Quality control}

Prior to assimilation, the GlobColour products are automatically quality controlled and processed using the Met Office Observation Processing System (OPS). This is the same procedure used for the physical variables assimilated by FOAM (Storkey et al., 2010), and is outlined below. A Gaussian error distribution is assumed by both the OPS and the assimilation scheme. This assumption is invalid for chlorophyll, because phytoplankton biomass follows a logarithmic distribution in nature (Barnes et al., 2011; Campbell, 1995). However, log-transforming the chlorophyll data normalises it, and so makes the assumption of Gaussian errors a reasonable approximation. Therefore both the OPS and the assimilation use $\log _{10}$ (chlorophyll) rather than chlorophyll. Whilst a good approximation, log-transformation does not guarantee a Gaussian error distribution, potentially impacting on the optimality of the assimilation (Bocquet et al., 2010). An alternative approach, which has been used in some biogeochemical data assimilation studies, is to use anamorphic transformations (Brankart et al., 2012), and this or similar approaches could be explored in the future.

As stated in Sect. 3.1, each observation comes with a set of confidence flags, as described fully in the GlobColour Product User Guide. The OPS rejects an observation if a flag is set marking no measurement, invalid measurement or a grid box which contains greater than $50 \%$ land. Further quality control is performed as described in Ingleby and Huddleston (2007) and Ingleby and Lorenc (1993). The main component of this is a background check, in which each observation is compared to a background field of $\log _{10}$ (chlorophyll). A probability of gross error (PGE) given the background value is calculated following Eq. (1) of Ingleby and Huddleston (2007): 

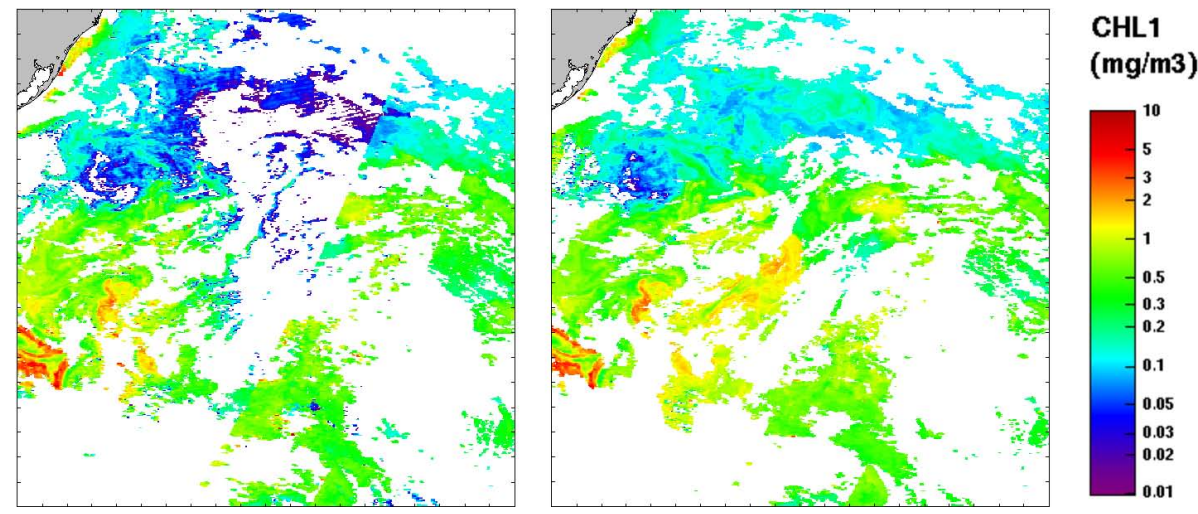

Fig. 2. Merged GlobColour products for $52^{\circ} \mathrm{W}-32^{\circ} \mathrm{W}, 48^{\circ} \mathrm{S}-28^{\circ} \mathrm{S}$ (South Atlantic) on 19 October 2008, generated using the ESA and NASA reprocessings used for this paper (left-hand plot); and the most recent reprocessings (right-hand plot). This merges, from left to right, a SeaWiFS swath at 16:41 UTC, a MODIS swath at 17:04 UTC, a SeaWiFS swath at 15:03 UTC, and a MERIS swath at 11:26 UTC.

$$
\begin{aligned}
P(G \mid O)= & \kappa P(G) /\left(\kappa P(G)+(2 \pi V)^{-0.5}\right. \\
& \left.\exp \left(-(o-b)^{2} / 2 V\right)(1-P(G))\right)
\end{aligned}
$$

where $\kappa$ is the density of the probability distribution of gross error due to instrument error, and is set here to be $0.1 ; P(G)$ is the PGE due to instrument error, and is set here to be 0.04 ; $V$ is the sum of the background and observation error variances; $o$ is the observation value and $\mathrm{b}$ is the background value. If $P(G \mid O)$ is greater than a specified threshold, set here to be 0.5 , then the observation is rejected. The background field used in this study is a monthly climatology produced by the authors from the GlobColour merged products. Daily chlorophyll values were averaged onto a $1^{\circ}$ grid, and the mean for each month was taken over the period 19982007. In an operational system, the previous day's one-day forecast could be used as the background, rather than the climatology. The background error variances are the same as those used in the assimilation scheme, and are described in Sect. 5.2. The observation error variances are the square of the observation errors specified in the GlobColour products. These are used rather than those described in Sect. 5.2 (which could alternatively be used), as this allows the quality control to benefit from the exact error information that is provided for each observation.

Once the quality control is completed, "super-obbing" is performed. This groups together observations within a $13 \mathrm{~km}$ range, and takes the median to create a single "superobservation", which is used by the assimilation. This is done because assimilating many high-resolution observations, which represent small-scale variability the model cannot resolve, can introduce noise into the model and degrade the solution. Furthermore, the assimilation scheme assumes observation errors to be uncorrelated, and the super-obbing process reduces any such correlations that might exist, as well as reducing random error (Berger et al., 2011; Purser et al., 2000).

\subsection{Assimilation}

There are three stages in producing a daily analysis, which are the same for both the physical and biogeochemical variables. Firstly, the model is run for a day with the observation operator applied. Secondly, the assimilation scheme is run and the increments are calculated. Thirdly, the model is run again for the same day, and the increments are applied.

In stage one, the observation operator performs a comparison between observation and model values using a first guess at appropriate time (FGAT) technique (Martin et al., 2007). This bilinearly interpolates model values to observation locations at the closest model time step to the observation time. For the merged GlobColour products, in which no time information is supplied, the chlorophyll observations are taken to be valid at 12:00 UTC. The model and observation values, along with the observation location and time, are saved to a file which is passed to the assimilation scheme. These files are also used for validation purposes.

In the second stage, the assimilation scheme produces a set of 2-D surface $\log _{10}$ (chlorophyll) increments using the same method as for sea surface temperature (SST). A detailed description of the process is given in Martin et al. (2007), as are the specific details for each of the physical variables assimilated. The scheme uses a variant of OI known as analysis correction (Lorenc et al., 1991), which uses an iterative method to solve the generalised OI analysis equation:

$\boldsymbol{x}_{\mathrm{a}}=\boldsymbol{x}_{\mathrm{b}}+\mathbf{B H}^{T}\left(\mathbf{H B H}^{T}+\mathbf{R}\right)^{-1}\left(\boldsymbol{y}-h\left(\boldsymbol{x}_{\mathrm{b}}\right)\right)$

where $\boldsymbol{x}_{\mathrm{a}}$ and $\boldsymbol{x}_{\mathrm{b}}$ are state vectors containing values of $\log _{10}$ (chlorophyll) at each surface model grid point; $\boldsymbol{x}_{\mathrm{a}}$ is the analysis, and $\boldsymbol{x}_{\mathrm{b}}$ is the background, which is the best estimate of the $\log _{10}$ (chlorophyll) field prior to assimilation, in this case the one-day forecast produced by the initial runthrough of the model; $\boldsymbol{y}$ is a vector containing the observations, $h$ is the observation operator, and $\mathbf{H}$ is the Jacobian of the observation operator; $\mathbf{B}$ and $\mathbf{R}$ are matrices of model and 
observation error covariances respectively, and will be discussed in Sect. 5.2. The increments are given by $\boldsymbol{x}_{\mathrm{a}}$ minus $x_{\mathrm{b}}$.

From the surface $\log _{10}$ (chlorophyll) increments, a set of 3$\mathrm{D}$ increments for each of the biogeochemical state variables is calculated using the nitrogen balancing scheme described in detail in Hemmings et al. (2008). This process is shown schematically in Fig. 3. The surface $\log _{10}$ (chlorophyll) increments are converted to surface phytoplankton increments using the model's nitrogen to chlorophyll ratio. This is calculated from a fixed carbon to nitrogen ratio and the variable carbon to chlorophyll ratio (see Table A1 and Sect. 2). The phytoplankton increments are then used to determine surface increments for the other nitrogen tracers (nitrate, zooplankton and detritus). The nitrogen balancing scheme assumes that phytoplankton errors result from a combination of growth errors and loss errors, and uses the background state, including the phytoplankton specific growth and loss rates, to determine whether growth or loss errors dominate. Increments are then partitioned between nitrate, zooplankton and detritus accordingly, to try and reduce these errors. This is subject to the constraint that where possible, nitrogen should be conserved at every grid point. The aim is to propagate the changes in chlorophyll as realistically as possible to the rest of the model, reducing not just the chlorophyll errors, but also their causes. The surface increments are applied to each model level above the mixed layer depth. Below this depth the increments are a combination of "primary" and "secondary" increments. The primary increments are based on the surface increments scaled to the background field at that depth. The secondary increments, which are only applied if the primary increments will create an unrealistic sub-surface nitrate minimum, are based on the expectation that nitrate concentrations increase monotonically with depth. The DIC increments are derived from the phytoplankton, zooplankton and detritus increments, using a set of constant carbon to nitrogen ratios (see Table A1). This conserves total carbon at each grid point. The alkalinity increments are set to be opposite in sign and equal in magnitude to the nitrate increments. The same parameter set is used as in Hemmings et al. (2008).

Finally in stage three, the physical and biogeochemical increments are applied evenly over the day using the incremental analysis update (IAU; Bloom et al., 1996) technique. This applies an equal proportion of the increments at each time step, rather than applying the entire increments at the first time step, which reduces the likelihood of the increments causing an instability in the model.

\section{Hindcast experiments}

In order to assess the impact of assimilating the GlobColour products, two hindcasts have been performed. These hindcasts, and the initialisation of the model and assimilation, are described below.

\section{$5.1 \quad$ Spin-up}

The initial conditions for this study were taken from a previous FOAM-HadOCC hindcast, performed as part of a different study. Fields from the end of this run, valid for $31 \mathrm{De}-$ cember 2006, were used. However, the nitrate field differed significantly from climatology, and so was replaced by the World Ocean Atlas 2005 (Garcia et al., 2006) climatology for January, interpolated to the model grid. A year-long spinup was then performed for 2007, in which no ocean colour data were assimilated. Whilst shorter than ideal, this length of spin-up was sufficient for "normal" model behaviour to be reached, with imperfect initial conditions being one of the sources of error that data assimilation aims to compensate for.

All runs performed in this study, including the spin-up, assimilated temperature, salinity and sea ice concentration data, but not SLA data. There are two reasons for this. Firstly, SLA data are used to give information about mesoscale eddies, which the $1^{\circ}$ resolution model is unable to resolve. Secondly, assimilating SLA data changes the position of isopycnal levels in the model. A scheme has yet to be developed to alter the biogeochemistry accordingly, so the physical and biogeochemical fields can become inconsistent, causing mixing which results in spurious sub-surface chlorophyll maxima.

In previous experiments, FOAM-HadOCC has shown sensitivity to biogeochemical increments applied near sea ice. This is because in regions where the ice has recently melted there can be very low model chlorophyll values compared to observations. The use of $\log _{10}$ (chlorophyll) in the assimilation accentuates these differences, resulting in extremely large increments. This information is propagated to nearby grid squares where model chlorophyll values are higher, resulting in anomalously high concentrations. Therefore in this study no chlorophyll observations at latitudes higher than $60^{\circ}$ north or south were assimilated, although biogeochemical increments generated from observations at lower latitudes were still applied in these regions, except in grid squares containing sea ice.

\subsection{Calculation of error covariances}

An important part of the data assimilation scheme is the background and observation error covariances. These determine the magnitude of the increments, and how much they are spread out onto the model grid. As detailed in Martin et al. (2007), FOAM requires sets of "mesoscale" and "synoptic scale" background error variances for each model grid point, which describe small- and large-scale model error variability respectively. For each, a correlation length scale must be specified, which determines how much an increment is spread to nearby grid points. A set of observation error variances is also needed. These contain both a contribution from instrument error and a contribution from 


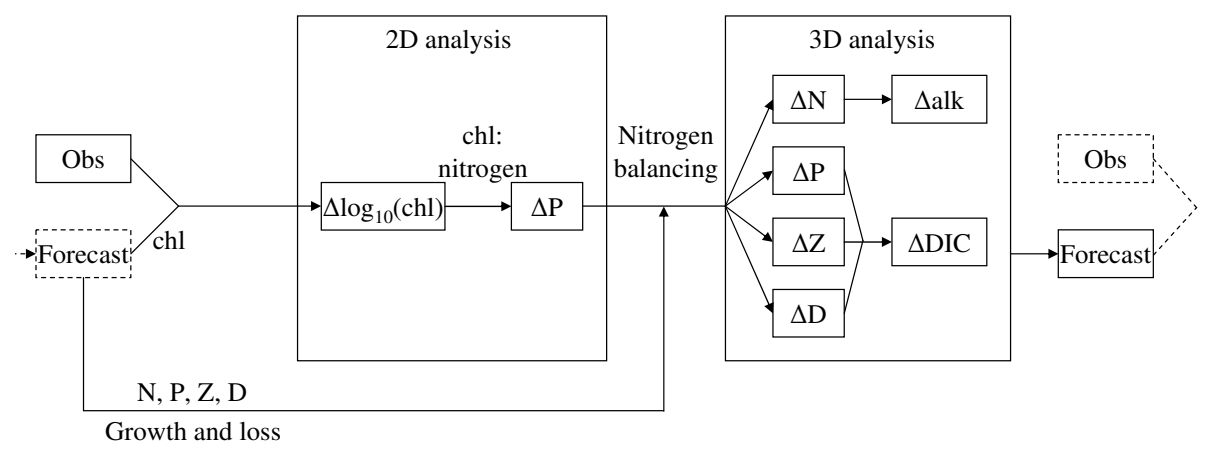

Fig. 3. Schematic of the chlorophyll assimilation scheme. $\Delta$ signifies increment, chl=chlorophyll, $\mathrm{N}=$ nutrients, $\mathrm{P}=$ phytoplankton, $\mathrm{Z}=$ zooplankton, $\mathrm{D}=$ detritus, alk = alkalinity, DIC = dissolved inorganic carbon, Obs = chlorophyll observations.

"representativeness" error - error arising from small-scale processes captured by the observations which the model is unable to resolve. This means that the errors specified in the GlobColour products cannot be directly used for this purpose, as they do not indicate representativeness error.

For the FOAM assimilation scheme, the error covariances must be specified a priori. However, to calculate these accurately requires performing a run with assimilation (which requires error covariances). Initial error variance estimates for $\log _{10}$ (chlorophyll) were therefore produced by calculating the standard deviation of the GlobColour merged products on a $1^{\circ}$ grid for the period 1998-2007, performed on a monthly basis to account for seasonal variation. These standard deviations were converted to variances, and at each grid point the observation error variance was set to $50 \%$ of the variance in the GlobColour data, and the mesoscale and synoptic scale error variances each set to $25 \%$ of the variance in the GlobColour data. This approach ensured that the highest error variances were in the regions with the highest chlorophyll variability, as would be expected. Whilst imperfect, these error variances allowed an assimilative run to be performed, producing more accurate chlorophyll fields than a run without assimilation. The correlation length scales were chosen to be the same as for SST $(100 \mathrm{~km}$ for the mesoscale and $400 \mathrm{~km}$ for the synoptic scale). Changes in chlorophyll often occur on smaller scales than this, but it is undesirable to set the mesoscale length scale to be much shorter than $100 \mathrm{~km}$ for a $1^{\circ}$ model, as "mesoscale" refers here to smallscale processes resolved by the model, and is not intended to be a direct representation of the ocean mesoscale (Martin et al., 2007). However, future improvements might be expected through tuning of these length scales.

In order to calculate a more accurate set of observation and background error variances, a run was performed for 2008 which assimilated the chlorophyll products using the initially specified error covariances, and which produced a two-day forecast each day. Using the results from this run, a new set of monthly error variances were calculated using a combination of the National Meteorological
Center (NMC) method (Parrish and Derber, 1992) and the Hollingsworth-Lönnberg (HL) method (Hollingsworth and Lönnberg, 1986). The NMC method provides estimates of the two (mesoscale and synoptic scale) components of the background error by calculating the differences between oneday and two-day forecasts valid for the same time. These are given at every grid point, as is required. The HL method uses observation minus model differences to calculate estimates of both the background and observation error variances. Being based on observations of the true ocean state, this normally produces more accurate error values. However, estimates can only be calculated at grid points where there are sufficient observations. Therefore the two methods were combined, with the NMC method used to give the spatial patterns in the error variances, and the HL method used to give the magnitudes. Mesoscale and synoptic scale background error variances were first calculated with the NMC method. To give a complete field, and to ensure consistency with the background errors, these mesoscale error variances were also used as a basis for the observation error variances. Each of the three sets of error variances were then scaled so that their global mean is identical to the global mean of the corresponding HL estimates.

These newly calculated background and observation error covariances are the ones used in the runs described below. To ensure consistency with the assimilation, and the best possible quality control, the observations were reprocessed by the OPS using the new background error variances, as described in Sect. 4.1.

\subsection{Main runs and experiment details}

Two hindcasts have been performed for the year 2008, taking initial conditions from the spin-up described in Sect. 5.1. One hindcast (hereafter "Assim") assimilated the GlobColour chlorophyll data, and a control run (hereafter "Control") assimilated no chlorophyll data. These runs were identical in every other respect, including the assimilation of physical data, with the aim of assessing the impact of the assimilation of chlorophyll data on the biogeochemical model. 
The statistics used to assess the results in this paper are mean model minus observation error (bias), root mean squared error (RMSE), Pearson's correlation coefficient $(r)$ and normalised standard deviation $\left(s_{n}\right.$; model standard deviation divided by observation standard deviation). Taylor plots (Taylor, 2001) are also used. These summarise RMSE, correlation and normalised standard deviation on a single diagram. The unbiased (centred) RMSE, normalised by the observation standard deviation, is given by radial distance from 1.0 on the $\mathrm{x}$-axis. The normalised standard deviation is given by distance from the curved dashed line between 1.0 on the $\mathrm{x}$-axis and 1.0 on the $\mathrm{y}$-axis. The correlation is obtained by drawing a line from the origin through a plotted point, and reading off where this meets the curved upper-axis. A perfect match between model and observations would be plotted at 1.0 on the $\mathrm{x}$-axis.

\section{Results}

When assessing the skill of a data assimilation scheme there are three main things to check. First of all, that the assimilation propagates the information from the observations correctly, so that the model results match the assimilated observations more closely, ideally within the observation error. Individual observations can either be compared to the analysis after they have been assimilated, or to the background field prior to assimilation. In this latter case the errors are equivalent to one-day forecast errors, and the observations can be considered to be semi-independent, as they have not yet contributed to the model field. However, the assimilative model run will still be intrinsically linked with these observations, because the observation errors are likely to be timecorrelated with those of observations assimilated on previous days. Therefore, fully independent observations are required in order to provide tangible evidence that the assimilation has improved the model's representation of the assimilated variable. Finally, it must be checked that the non-assimilated model variables are also improved by the assimilation, or at least not degraded. Improvements in the assimilated variable may be worthless if the rest of the system suffers as a result.

Maps of annual average surface chlorophyll for Control, Assim and the GlobColour observations are shown in Fig. 4. In this simple visual comparison it can be clearly seen that Control is very different from the observations, whereas Assim matches them much more closely, in terms of both spatial pattern and magnitudes. In this sense, the assimilation can be considered a success.

Control has too much chlorophyll across most of the ocean, but too little chlorophyll in the Brazil-Malvinas confluence off the Patagonian coast, as well as north of about $50^{\circ} \mathrm{N}$. This is accentuated in Fig. 4 because most of the observations at high northern latitudes are taken during the Northern Hemisphere summer. An in-depth discussion of the reasons for these biases is outside the scope of this paper, but

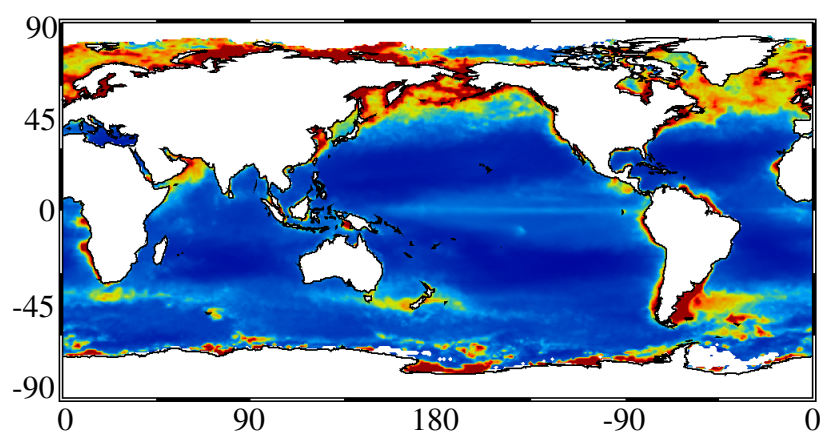

a) Observations

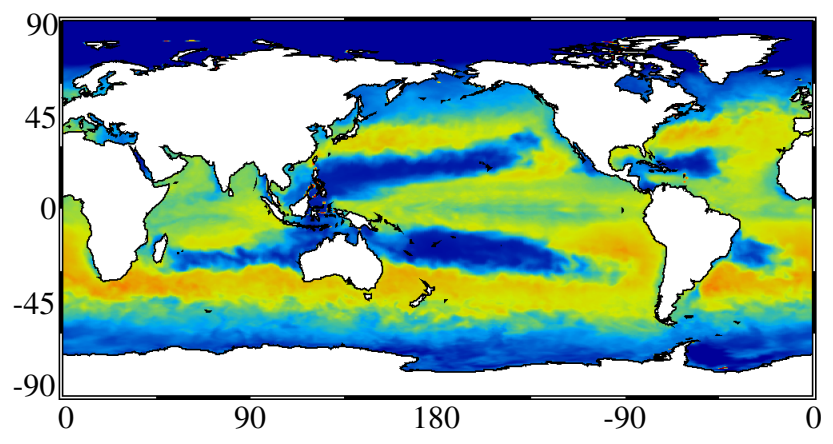

b) Control

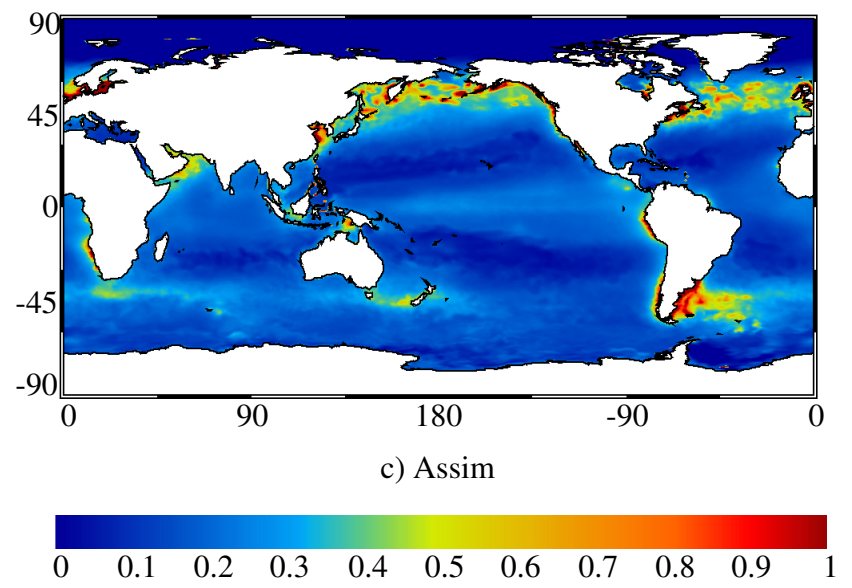

Fig. 4. Mean surface chlorophyll $\left(\mathrm{mg} \mathrm{m}^{-3}\right)$ for 2008 .

the overestimation of chlorophyll in most regions is linked to excess nutrient concentrations at the surface. A major contribution to this problem comes from the physical data assimilation. Equivalent simulations which do not include physical data assimilation match the observations better (not shown). This problem is not unique to the FOAM system (e.g. El Moussaoui et al., 2011; Anderson et al., 2000; Ourmières et al., 2009), and is related to excess mixing caused by the physical assimilation creating spurious vertical velocities and altering the isopycnal levels in the model, which is not accounted for by HadOCC. Despite these issues, physical data assimilation has been included in this study as it is a fundamental component of the operational FOAM system. 
Furthermore, whilst the physical assimilation is currently a source of error for the biogeochemistry, if these issues can be fixed (which is being worked on), then the demonstrable improvement the physical assimilation makes to the physical fields should in turn result in more accurate biogeochemical fields than if physical data were not assimilated. As it is, the chlorophyll assimilation is able to counteract these and other errors somewhat, propagating the increments such that model chlorophyll concentrations are either increased or decreased in a realistic manner. The chlorophyll errors in Assim are much lower than those in both Control and an equivalent hindcast with no data assimilation at all (not shown). Assim is not a perfect match for the observations, but should not be expected to be, as over-fitting to the observations can destroy the relationships between variables in the model, thus degrading forecast quality (Oke and Sakov, 2008). However, chlorophyll patterns in regions such as the Brazil-Malvinas confluence, which are not reproduced by Control, are captured well by Assim.

Figure 5 shows the model error for surface $\log _{10}$ (chlorophyll) when compared to the assimilated GlobColour observations. The model values have been interpolated to the observation locations using the observation operator to provide an exact like-for-like comparison. This has been performed prior to assimilation, so in this case the observations can be considered to be semi-independent, and the errors are equivalent to one-day forecast errors rather than analysis errors. Figure 5 shows time series of daily mean global bias and RMSE for Control and Assim. Included for comparison is the RMSE of the observations themselves, calculated from the values given in the GlobColour products. The signs of the observation errors are not known, so the observation bias cannot be plotted. It is clear that both model runs have too much chlorophyll compared to the observations. However, both the bias and RMSE are much lower for Assim than for Control, which indicates that the assimilation is having a positive impact on the modelled chlorophyll concentrations, as intended. The mean global bias for 2008 is $0.398 \log _{10}\left(\mathrm{mg} \mathrm{m}^{-3}\right)$ for Control and 0.119 $\log _{10}\left(\mathrm{mg} \mathrm{m}^{-3}\right)$ for Assim. The mean global RMSE is 0.586 $\log _{10}\left(\mathrm{mg} \mathrm{m}^{-3}\right)$ for Control and $0.314 \log _{10}\left(\mathrm{mg} \mathrm{m}^{-3}\right)$ for Assim. The correlation is also improved, from 0.261 for Control to 0.619 for Assim. This improvement is immediate, with the error considerably reduced after only a single day of assimilation. The error for Assim remains lower, and fairly constant, throughout the year, suggesting that Assim is performing well at capturing the seasonal cycle. For the initial hindcast used to calculate the error covariances, described in Sect. 5.2, the mean global RMSE was 0.439 $\log _{10}\left(\mathrm{mg} \mathrm{m}^{-3}\right)$, demonstrating the importance of using error covariances designed specifically for use with the model configuration.

Both the bias and RMSE of Control are higher than the errors of the observations, as is the RMSE of Assim. However, the bias of Assim is lower than the RMSE of the

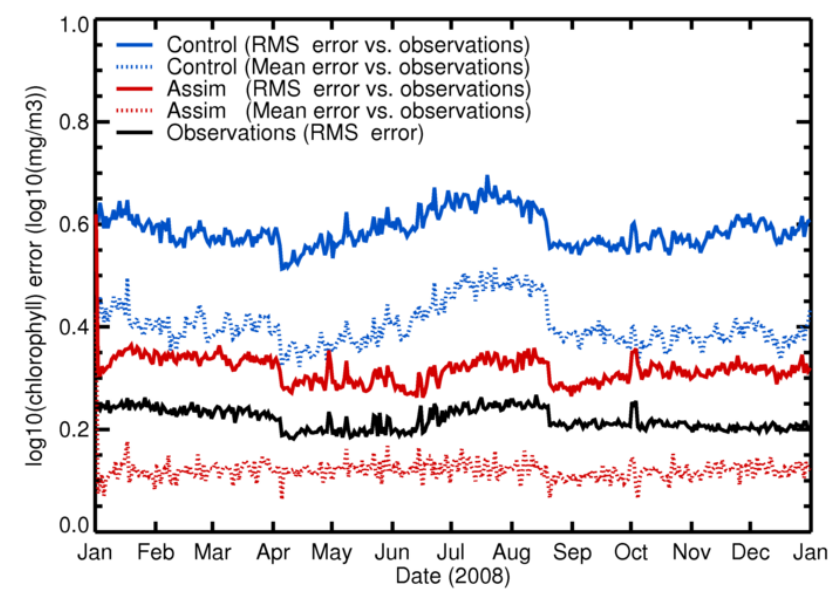

Fig. 5. Time series of global model and observation error for 2008. The solid lines represent RMSE, the dotted lines represent bias. The blue and red lines represent the error in Control and Assim respectively when compared to the GlobColour observations on the observation operator step prior to assimilation each day. The black line is the root mean squared of the observation errors specified in the GlobColour files.

observations, which is what the assimilation would expect to achieve. It would be hoped that this bias would be very close to zero. Whilst not the case for $\log _{10}$ (chlorophyll), it is the case for chlorophyll, for which the mean global bias for 2008 is $0.190 \mathrm{mg} \mathrm{m}^{-3}$ for Control and $0.008 \mathrm{mg} \mathrm{m}^{-3}$ for Assim.

It can be seen that the RMSE for the observations and for both model runs follows a very similar pattern throughout the year. In particular there are sudden decreases at the beginning of April and in mid-August, corresponding to the introduction of SeaWiFS data; and a peak in early October, corresponding to two days where there are no SeaWiFS data. As discussed in Sect. 3.2, the inclusion of SeaWiFS data changes the mean daily global chlorophyll concentration in the merged observations. It is likely that the quality of the model simulations have not significantly changed in comparison to reality, it merely appears that way because the measure of truth has changed.

A Taylor plot for $\log _{10}$ (chlorophyll), using the same model-data comparisons as Fig. 5, is shown in Fig. 6. As well as a global average, Fig. 6 provides a comparison for different regions, to see how the assimilation affects the model in each ocean basin. Across all regions, both unbiased RMSE and correlation are improved in Assim, with similar values obtained in each basin, indicating that Assim has comparable skill across the entire model domain, which is less clearly the case for Control. However, whilst the unbiased RMSE and correlation are improved in all areas, the normalised standard deviation generally remains similar, and is even made worse in some regions, including for the global average. In all cases the standard deviation is too low for Assim, suggesting that the assimilation may be smoothing out too much of the variability in the model. 


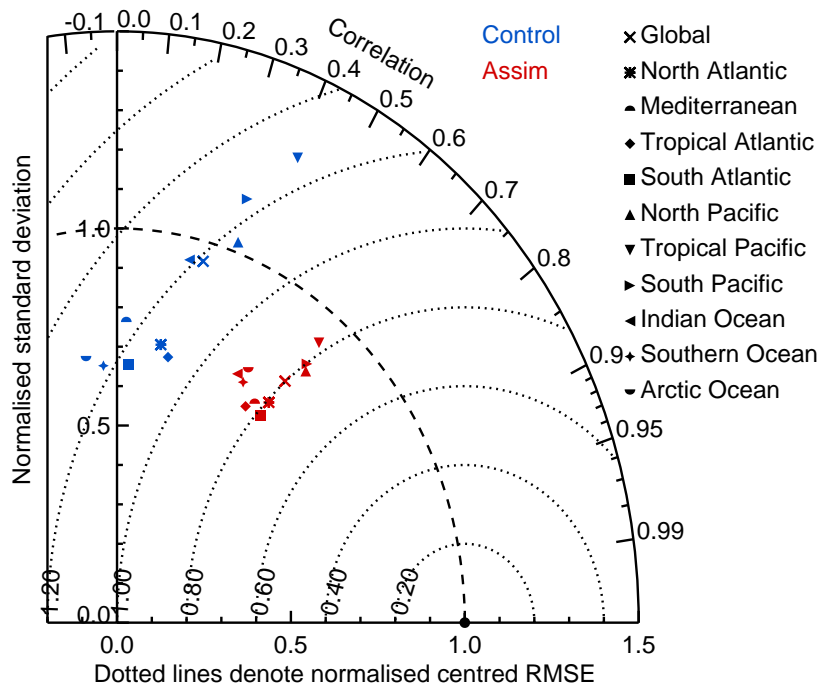

Fig. 6. Taylor plot showing skill in each ocean basin for Control and Assim when compared to the GlobColour observations on the observation operator step prior to assimilation each day.

The assimilation has clearly improved the model's simulation of surface chlorophyll compared to the assimilated observations, throughout the year and across all ocean basins. However, as previously stated, comparisons to independent observations are required in order to have full confidence in the assimilation's impact. In situ observations of biogeochemical properties are sparse, but there are some data sets available for validation purposes. One of these is the SeaWiFS Bio-Optical Archive and Storage System (SeaBASS; Werdell et al., 2003), developed by NASA to enable assessment of SeaWiFS products. SeaBASS collects in situ chlorophyll and radiance observations, as well as associated measurements, from a large range of cruises and time series stations. The SeaBASS chlorophyll data have been used as part of the error characterisation for calibration of the GlobColour products, so are not strictly independent, but the dependency will be much lower than that on the assimilated observations.

Figure 7 shows quantile-quantile plots for Control and Assim against SeaBASS observations of $\log _{10}$ (chlorophyll) at the surface of the ocean. A quantile-quantile plot is a measure of how well the distribution of model values matches the distribution of observation values, with an exact fit lying on the one-to-one line. Only those observations taken in 2008 in the open ocean (bottom depth greater than $1000 \mathrm{~m}$, chosen to be consistent with Bailey and Werdell, 2006) were used in this comparison, as neither the model nor the assimilated satellite observations are valid for shallow waters. The daily averaged model field for the date each observation was made has been interpolated to the observation location, providing an exact spatial comparison. Consistent with the comparisons to satellite observations, Control generally has too much chlorophyll compared to the SeaBASS observations, whilst Assim

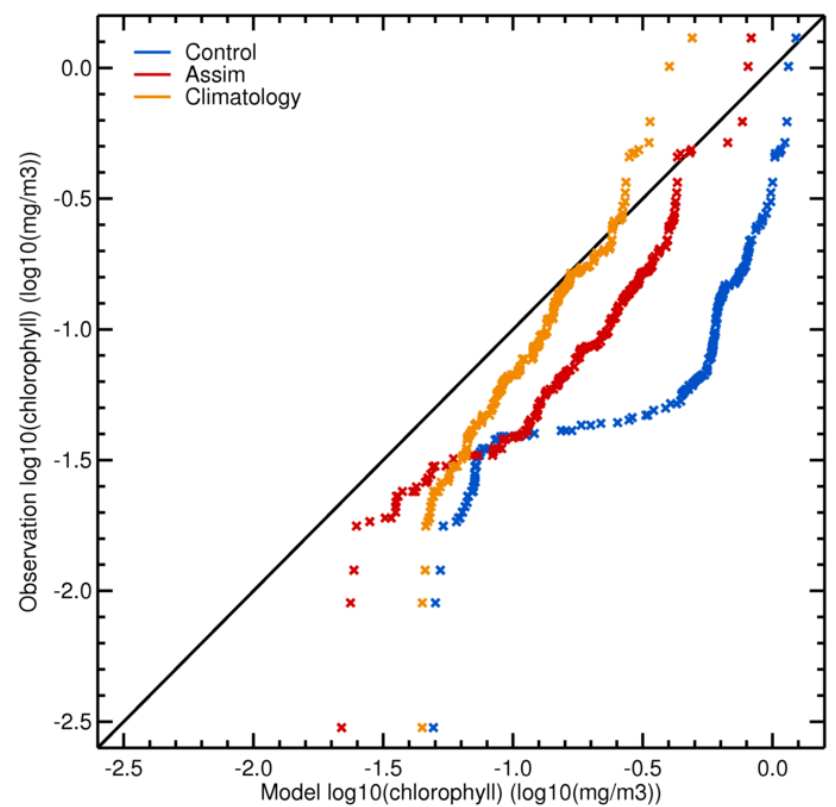

Fig. 7. Quantile-quantile plot versus surface SeaBASS $\log _{10}$ (chlorophyll) for Control (blue), Assim (red) and climatology (gold). A map of observations used for the comparison is given in Fig. A1a.

matches the observations much better for the entire range of chlorophyll concentrations. This demonstrates that the assimilation has improved the model's representation of surface chlorophyll when compared to these independent observations. Figure 7 also shows the equivalent comparison for the monthly chlorophyll climatology derived from GlobColour observations described in Sect. 4.1. This provides a better fit to the observations than Assim, except at high or low observed concentrations, indicating that further improvements are required to FOAM-HadOCC.

Assim's improved representation of surface chlorophyll in comparison to the SeaBASS observations is confirmed by the statistics shown in Table 1, with the bias, RMSE, and correlation all better for Assim than for Control. Climatology matches the SeaBASS observations better than Assim though, with a lower bias and RMSE, and higher correlation. However, climatology also has a normalised standard deviation of 0.597 which, in conjunction with Fig. 7, suggests that it does not represent the variability in the observations as well as Assim.

Assim not only does a better job than Control of reproducing the SeaBASS chlorophyll observations at the surface, but also improves the representation of chlorophyll beneath the surface, as shown by the statistics given in Table 1 . RMSE, correlation and normalised standard deviation are all improved, and there is a slight reduction in bias. This demonstrates that the assimilation is correctly propagating the information from the assimilated observations down through the water column, providing a more realistic representation 
Table 1. Statistics versus SeaBASS $\log _{10}$ (chlorophyll) $\left(\log _{10}\left(\mathrm{mg} \mathrm{m}^{-3}\right)\right)$ observations at open ocean points (bottom deeper than $1000 \mathrm{~m}$ ). A map of observations used for the surface comparison is given in Fig. A1a, and for the all depths comparison in Fig. A1b.

\begin{tabular}{lrrrrrr}
\hline & \multicolumn{3}{c}{$\begin{array}{c}\text { Surface } \\
(192 \text { observations })\end{array}$} & & \multicolumn{2}{c}{$\begin{array}{c}\text { All depths } \\
(1867 \text { observations })\end{array}$} \\
\cline { 2 - 3 } \cline { 7 - 8 } & Control & Assim & Climatology & & Control & Assim \\
\hline Bias & 0.659 & 0.312 & 0.141 & & -0.301 & -0.297 \\
RMSE & 0.885 & 0.536 & 0.366 & & 0.938 & 0.812 \\
$r$ & -0.137 & 0.249 & 0.473 & & 0.512 & 0.599 \\
$s_{\mathrm{n}}$ & 1.065 & 0.868 & 0.597 & & 1.315 & 1.218 \\
\hline
\end{tabular}

of the variable beneath the surface, even where there are no satellite observations to assimilate.

A further source of in situ observations is the Hawaii Ocean Time-series (HOT) data set, with approximately monthly measurements made at the A Long-term Oligotrophic Habitat Assessment (ALOHA) site at $22.75^{\circ} \mathrm{N}$, $158.00^{\circ} \mathrm{W}$. These are fully independent from the model. Comparisons between model results and these observations have been made by horizontally and vertically interpolating the model values to the observation locations. The statistics in Table 2 show that the bias, RMSE and correlation for fluorometrically derived $\log _{10}$ (chlorophyll) against all observations are improved for Assim compared to Control. The impact is greatest when the comparison is restricted to the surface $50 \mathrm{~m}$, where the normalised standard deviation is also positively affected by the assimilation, but is still seen beneath this depth, showing the assimilation to have a beneficial effect throughout the water column.

Another source of independent in situ chlorophyll observations is the Atlantic Meridional Transect (AMT) cruises. In 2008 a cruise left the United Kingdom on 3 October, travelled south through the Atlantic, and reached the Falkland Islands on 10 November, taking measurements at regular intervals along the way. The statistics for $\log _{10}$ (chlorophyll), at all depths, are shown in Table 2. Compared to Control, the bias, RMSE, correlation and normalised standard deviation are all improved in Assim. Separating out the top $50 \mathrm{~m}$ and the remaining depths shows the greatest improvements to be near the surface, with Control and Assim being of comparable accuracy beneath $50 \mathrm{~m}$.

The comparisons made to satellite and in situ chlorophyll observations give a great deal of confidence that the assimilation is improving the model's representation of chlorophyll, both at and beneath the surface of the ocean. Having established this, the impact the assimilation has on the remaining model variables must be assessed. This is an important check, as it is desirable for the assimilation to improve all model variables. Furthermore, data assimilation has the potential to degrade other model variables, which would not only make the model less useful for creating analyses of these, but could also lead to less accurate forecasts of chlorophyll than if no assimilation had occurred.

Figure 8 shows cross-sections of each of the model state variables for Control and Assim, along with the corresponding assimilation increments. The section plotted is the upper $100 \mathrm{~m}$ of the Atlantic Ocean from $77^{\circ} \mathrm{S}$ to $68^{\circ} \mathrm{N}$ at a longitude of $30^{\circ} \mathrm{W}$, and the data shown are mean values for May 2008, at the height of the North Atlantic spring bloom. This serves to demonstrate the impact the assimilation has beneath the surface over a wide geographical domain, and which changes are directly due to the increments, and which result from the biogeochemical model dynamics adjusting to the increments. As described in Hemmings et al. (2008) and summarised in Sect. 4.2, the assimilation scheme creates increments for the six biogeochemical state variables based on a principle of conserving nitrogen and carbon at each grid point. This is dependent on the background state and the phytoplankton growth and loss rates, which the scheme uses to determine whether the phytoplankton error is primarily due to errors in the growth rate or errors in the loss rate.

In Assim (Fig. 8b), phytoplankton concentration is reduced compared to Control (Fig. 8a) throughout the mixed layer south of about $60^{\circ} \mathrm{N}$, and is increased further north, consistent with the changes in chlorophyll. Beneath the mixed layer a sub-surface phytoplankton maximum is created, which stretches from the Equator to approximately $45^{\circ} \mathrm{N}$, and persists throughout much of the year. Without any observations to compare against, it is difficult to know whether this sub-surface maximum actually occurred in the ocean, and thus whether the assimilation increments below the mixed layer are large enough.

In Control (Fig. 8d) there is a region of high zooplankton concentration between about $15^{\circ} \mathrm{S}$ and $40^{\circ} \mathrm{N}$, down to a depth of around $50 \mathrm{~m}$. In Assim (Fig. 8e) this is reduced equally at all depths, despite large positive zooplankton increments (Fig. 8f) in this area, which are created to balance the nitrogen lost by decreasing the phytoplankton concentration. The model's reaction to the reduced phytoplankton outweighs the increases from the assimilation, which is desirable as it means that the model is maintaining a consistent relationship between phytoplankton and zooplankton. North of $40^{\circ} \mathrm{N}$, zooplankton concentrations are very low in Control, even where phytoplankton concentrations are high. It would be expected that zooplankton concentrations would also be high in this region, and these are considerably increased in Assim. This indicates that the use of data assimilation may be overcoming inadequacies in the chosen values of tuneable parameters. The change in zooplankton is further demonstrated in Fig. 9, which shows annual mean surface zooplankton fields from Control and Assim, equivalent to the chlorophyll fields shown in Fig. 4b-c. A very similar pattern of changes can be seen in both zooplankton and chlorophyll (and phytoplankton), as would be expected, indicating that the assimilation is having a favourable effect on the model zooplankton. A similar impact is seen on detritus (Fig. 8g-i). 

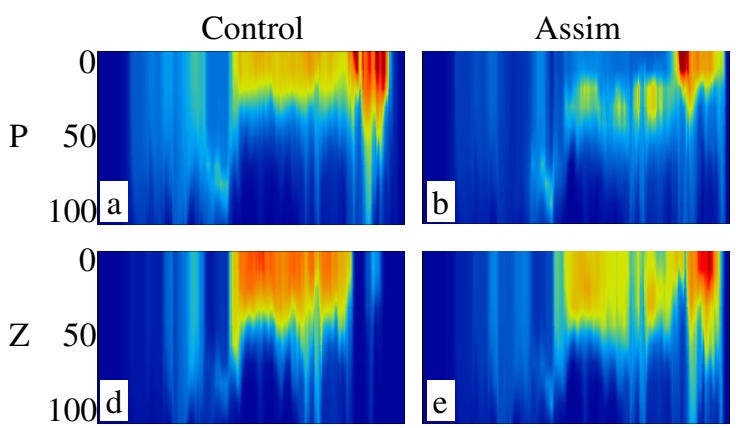

$\mathrm{D}$
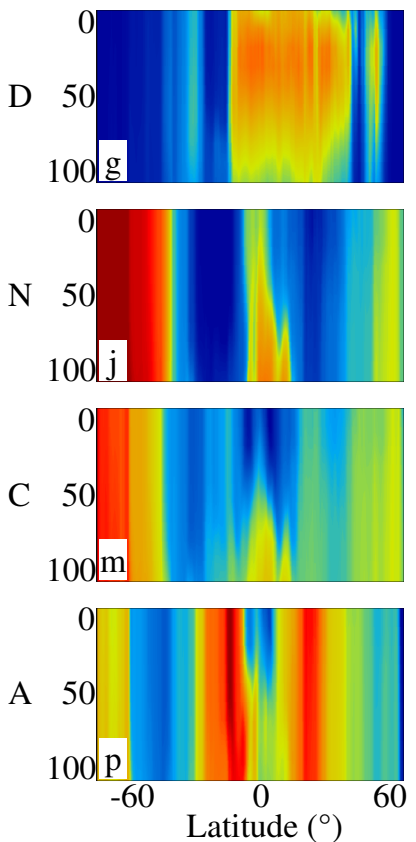
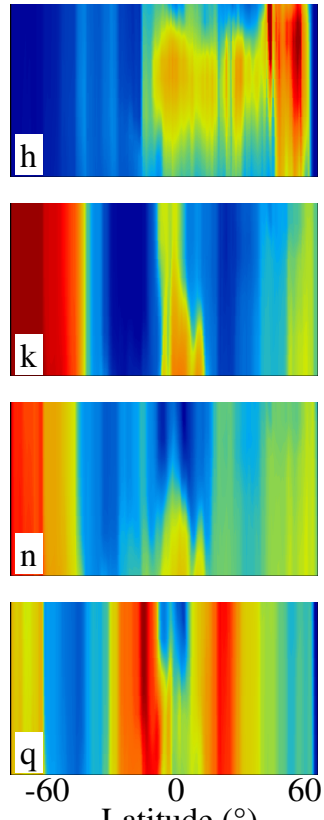

Increments
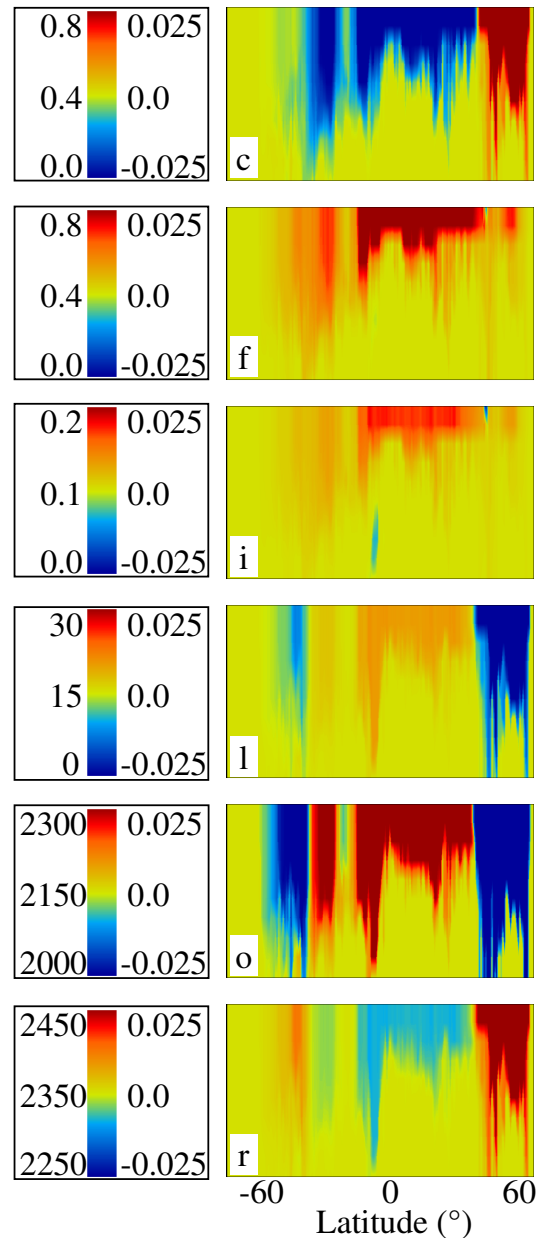

Fig. 8. Cross-sections down to $100 \mathrm{~m}$ depth for $77^{\circ} \mathrm{S}$ to $68^{\circ} \mathrm{N}$ along $30^{\circ} \mathrm{W}$ for May 2008. $\mathrm{P}=$ phytoplankton $\left(\mathrm{mmol} \mathrm{N} \mathrm{m}^{-3}\right.$; a-c), $\mathrm{Z}=$ zooplankton $\left(\mathrm{mmol} \mathrm{N} \mathrm{m}{ }^{-3} ; \mathbf{d}-\mathbf{f}\right), \mathrm{D}=$ detritus $\left(\mathrm{mmol} \mathrm{N} \mathrm{m}^{-3} ; \mathbf{g}-\mathbf{i}\right), \mathrm{N}=$ nutrients $\left(\mathrm{mmol} \mathrm{N} \mathrm{m}^{-3} ; \mathbf{j}-\mathbf{l}\right), \mathrm{C}=$ dissolved inorganic carbon $\left(\mathrm{mmol} \mathrm{C} \mathrm{m}{ }^{-3} ; \mathbf{m}-\mathbf{o}\right), \mathrm{A}=$ alkalinity $\left(\mathrm{meq} \mathrm{m}^{-3} ; \mathbf{p}-\mathbf{r}\right)$. For each variable (each row), Control and Assim have been plotted using the colour scale on the left of the colour bar, and the increments using the colour scale on the right of the colour bar. All the increments fields have been plotted using the same colour scale, even though this does not capture the full range for all fields, in order to allow a direct comparison between variables.

The nutrient field from Assim (Fig. 8k) is very similar to that from Control (Fig. 8j), except that in Assim there are fewer nutrients near the surface north of about $45^{\circ} \mathrm{N}$. It might be expected that the assimilation would produce large nutrient increments to balance the loss of phytoplankton, thereby accentuating nutrient biases. It is encouraging that this is not the case. The scheme is intepreting the positive error in phytoplankton as being due primarily to negative error in the loss rate rather than positive error in the growth rate, and so is increasing zooplankton concentrations more than nutrient concentrations. Because the assimilation is conserving nitrogen at each grid point, but the model has too much nitrogen at the surface, it can never properly correct the model error. However, it can be argued that significant model biases such as this should be addressed through model development, rather than data assimilation. It is also clear that the model is still able to produce zooplankton and detritus fields which are consistent with the reduction in phytoplankton. The DIC increments (Fig. 8o) follow a very similar pattern to the nutrient increments (Fig. 81), resulting in a reduction in DIC near the surface north of about $45^{\circ} \mathrm{N}$, and a slight increase near the surface south of this latitude. This is consistent with the changes to the other variables, and is to be expected. The alkalinity increments (Fig. 8r) are opposite in sign and equal in magnitude to the nutrient increments, meaning that the changes made to alkalinity are small in comparison to typical values, and little change to the field is seen.

Because observations of most biogeochemical variables are sparse, comparisons to climatology are required in order to gain an understanding of the large-scale abilities of 
Table 2. Statistics versus HOT ALOHA and AMT $\log _{10}$ (chlorophyll) $\left(\log _{10}\left(\mathrm{mg} \mathrm{m}^{-3}\right)\right)$ observations at open ocean points (bottom deeper than $1000 \mathrm{~m}$ ). For comparisons to AMT data, model values have been rounded to two decimal places before log-transformation, as this is the precision of the observations. A map of AMT observations used for the comparison is given in Fig. A1d.

\begin{tabular}{lccccc}
\hline & \multicolumn{2}{c}{ HOT ALOHA } & & \multicolumn{2}{c}{ AMT } \\
\cline { 2 - 3 } \cline { 5 - 6 } \cline { 5 - 6 } All depths & Control & Assim & & Control & Assim \\
\hline Bias & 0.105 & 0.040 & & 0.41 & 0.38 \\
RMSE & 0.545 & 0.516 & & 0.82 & 0.71 \\
$r$ & 0.667 & 0.707 & & 0.22 & 0.42 \\
$s_{\mathrm{n}}$ & 2.385 & 2.365 & & 1.39 & 1.35 \\
\hline $0-50 \mathrm{~m}$ & 58 observations & & 4393 observations \\
\hline Bias & 0.072 & 0.056 & & 0.99 & 0.71 \\
RMSE & 0.416 & 0.317 & & 1.14 & 0.83 \\
$r$ & 0.335 & 0.358 & & -0.08 & 0.57 \\
$s_{\mathrm{n}}$ & 1.945 & 1.432 & & 0.42 & 0.82 \\
\hline$>50 \mathrm{~m}$ & 124 observations & & 11647 observations \\
\hline Bias & 0.120 & 0.033 & & 0.19 & 0.25 \\
RMSE & 0.596 & 0.587 & & 0.67 & 0.65 \\
$r$ & 0.727 & 0.771 & & 0.27 & 0.40 \\
$s_{\mathrm{n}}$ & 2.507 & 2.576 & & 1.30 & 1.41 \\
\hline
\end{tabular}

the model. The 2009 World Ocean Atlas includes a climatology for nitrate (Garcia et al., 2010), the Global Ocean Data Analysis Project (GLODAP) provides climatologies for DIC and alkalinity (Key et al., 2004), and $p \mathrm{CO}_{2}$ and air-sea $\mathrm{CO}_{2}$ flux climatologies are provided by Takahashi et al. (2009). A Taylor plot summarising comparisons between annual average surface model fields and these annual climatologies is shown in Fig. 10. The nitrate, DIC and alkalinity climatologies are complete fields at $1^{\circ}$ resolution, and have been interpolated to the model grid for the comparison. The $p \mathrm{CO}_{2}$ and air-sea $\mathrm{CO}_{2}$ flux climatologies are complete fields at $5^{\circ}$ resolution and the model fields were regridded to match. In all cases grid points with bottom depth less than $1000 \mathrm{~m}$ were excluded. For DIC, alkalinity, and nitrate there is very little difference between Control and Assim in terms of the overall annual mean statistics. For both $p \mathrm{CO}_{2}$ and air-sea $\mathrm{CO}_{2}$ flux Assim has a slightly increased unbiased RMSE, but also a slightly increased correlation. From this, it can be concluded that the data assimilation has resulted in no major changes to the quality of these global annual mean fields.

A zooplankton climatology is available from the Coastal and Oceanic Plankton Ecology, Production, and Observation Database (COPEPOD; O'Brien, 2005). This is presented as a 2-D field at $1^{\circ}$ resolution, with zooplankton biomass values standardised to a $330 \mu \mathrm{m}$ mesh with a sampling depth interval of $0-200 \mathrm{~m}$. The climatology therefore represents

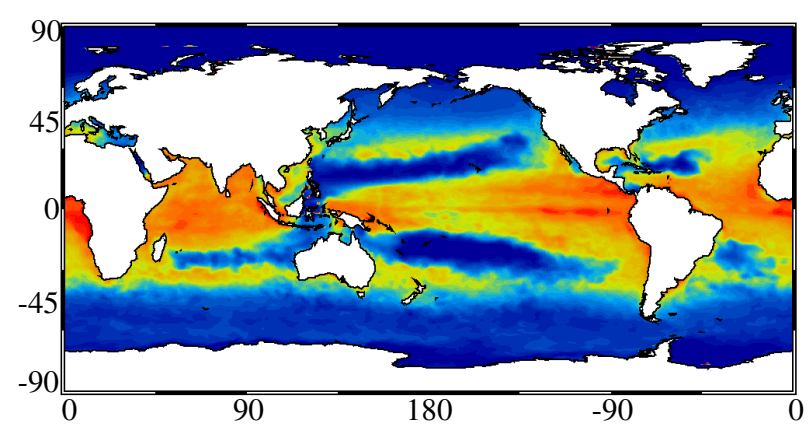

a) Control

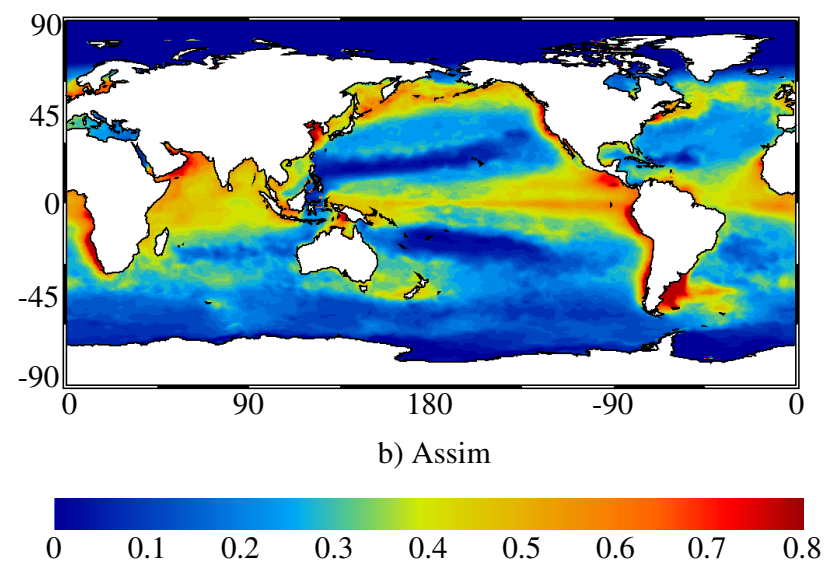

Fig. 9. Mean surface zooplankton concentration $\left(\mathrm{mmol} \mathrm{N} \mathrm{m}^{-3}\right)$ for 2008.

mesozooplankton concentration, and does not directly correspond to the zooplankton variable within HadOCC, which represents total zooplankton concentration. However, a positive correlation between HadOCC and COPEPOD zooplankton may still be expected, making the comparison worthwhile. Many grid points in the COPEPOD climatology contain missing data values, and so the annual average model field was interpolated to the climatology grid, summed over the surface $200 \mathrm{~m}$, and points with no corresponding values in the COPEPOD data set, or with bottom depth less than $1000 \mathrm{~m}$, excluded. The values in COPEPOD are given in units of $\mathrm{mg} \mathrm{C} \mathrm{m}^{-3}$, and were converted to the model units of $\mathrm{mmol} \mathrm{N} \mathrm{m}^{-3}$ using a carbon to nitrogen ratio of 5.625 , as used in HadOCC (see Table A1). The correlation between HadOCC and COPEPOD zooplankton was found to be -0.254 for Control, and 0.112 for Assim. These correlations are low for both model runs, possibly due to the aforementioned differences between the model and climatology, but suggest that the assimilation is at least not degrading the model zooplankton.

Comparisons have also been made to in situ observations of nitrate from the SeaBASS database. These were taken in the North Atlantic in April and May 2008, as shown in Fig. A1c. Figure 11 shows quantile-quantile plots comparing 


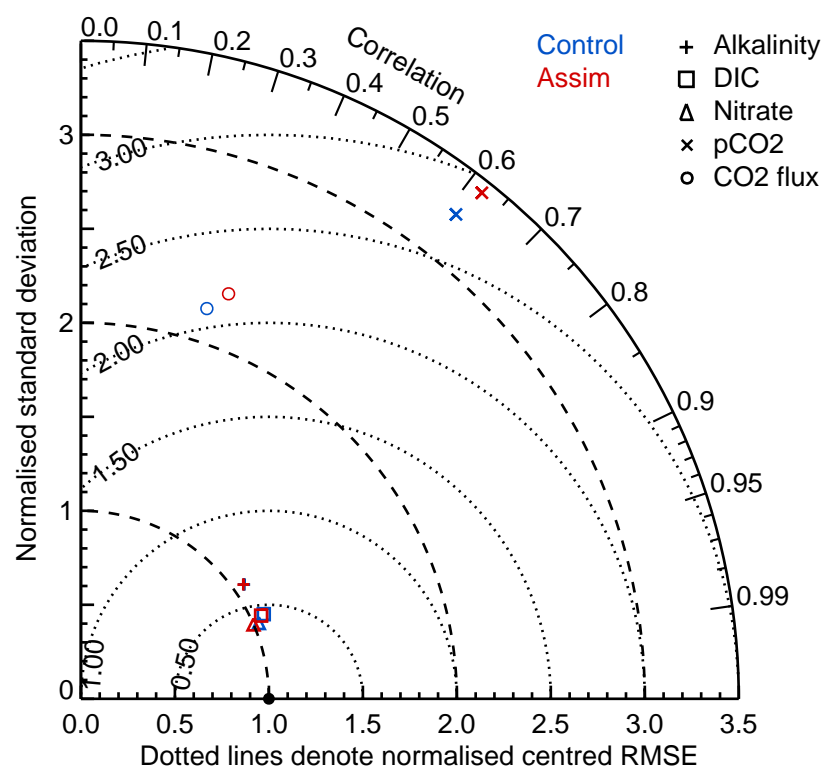

Fig. 10. Taylor plot comparing annual mean surface values from Control (blue) and Assim (red) to climatologies of alkalinity (+), DIC $(\square)$, nitrate $(\triangle), p \mathrm{CO}_{2}(\mathrm{x})$ and air-sea $\mathrm{CO}_{2}$ flux (o).

observations at all depths to nitrate from Control, Assim and the World Ocean Atlas 2009 climatology. The distributions of Control and Assim are both a poor fit to the distribution of the observations, displaying a much smaller range of values and generally overestimating low nitrate concentrations. However, the distribution of Assim is a better match to that of the observations than the distribution of Control is, suggesting that the assimilation has improved the model's representation of nitrate compared to the SeaBASS observations. This is supported by the statistics shown in Table 3. Assim has a lower bias and RMSE than Control, and a standard deviation which is a better match to that of the observations. Control does, however, have a higher correlation, possibly because Assim has more variability, but this does not always match that of the observations. As shown in Figs. 8j-1 and 10, the impact of the assimilation on the model nitrate is generally smaller than in the region where the SeaBASS observations were taken. Therefore comparison to a wider set of observations is required before an improvement can be conclusively demonstrated, although this would require validation over a longer period than the model has been run for in this study. It is interesting to note that whilst the climatology is clearly a better match to the SeaBASS observations than the model runs, it also suffers from the same bias and lack of variability as the model. It is known that the representation of nitrate in HadOCC is degraded by the physical data assimilation, and so if these problems are addressed it is hoped that HadOCC can provide better predictions of nitrate concentrations than climatology.

Observed profiles of DIC and alkalinity are available at the HOT ALOHA site. As demonstrated by the statistics in

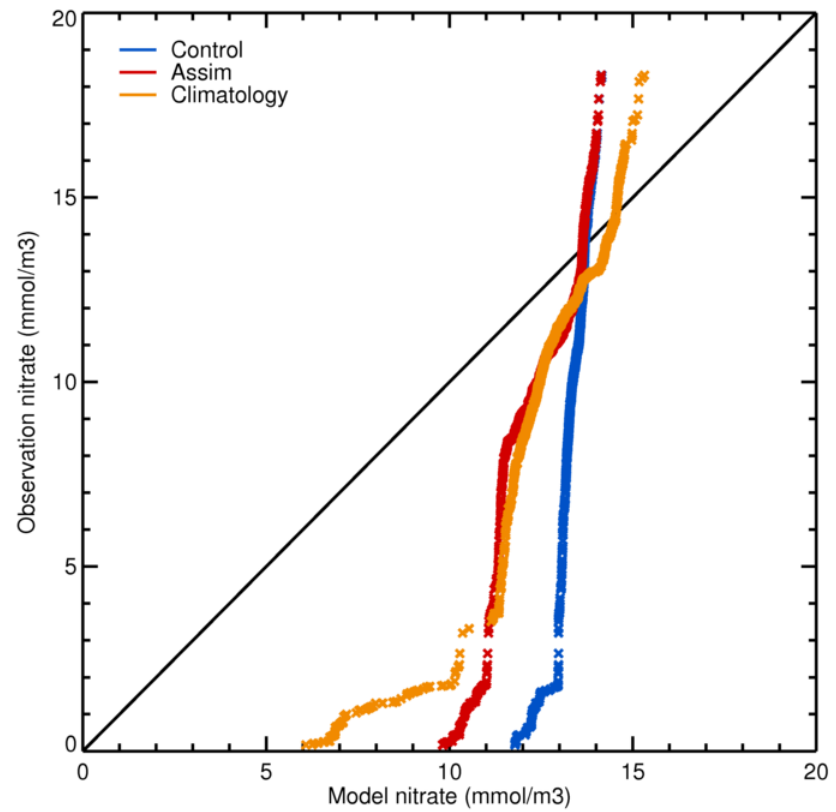

Fig. 11. Quantile-quantile plot versus SeaBASS nitrate for Control (blue), Assim (red) and climatology (gold). A map of observations used for the comparison is given in Fig. A1c.

Table 3. Statistics versus SeaBASS nitrate $\left(\mathrm{mmol} \mathrm{N} \mathrm{m}^{-3}\right)$, HOT ALOHA alkalinity $\left(\mathrm{meq} \mathrm{m}^{-3}\right)$, HOT ALOHA DIC $\left(\mathrm{mmol} \mathrm{C} \mathrm{m}^{-3}\right)$ and CARBON-OPS $p \mathrm{CO}_{2}$ ( $\mu \mathrm{atm}$ ) observations at open ocean points (bottom deeper than $1000 \mathrm{~m}$ ). 1096 nitrate, 121 alkalinity, 127 DIC and $915 p \mathrm{CO}_{2}$ observations were used in the comparisons, and maps of the SeaBASS and CARBON-OPS data are given in Fig. A1c and Fig. A1e, respectively.

\begin{tabular}{lrrrrr}
\hline & & Bias & RMSE & $r$ & $s_{\mathrm{n}}$ \\
\hline Nitrate & Control & 3.309 & 4.717 & 0.677 & 0.104 \\
& Assim & 2.477 & 4.088 & 0.478 & 0.272 \\
& Climatology & 2.469 & 3.580 & 0.751 & 0.449 \\
\hline \multirow{2}{*}{ DIC } & Control & -34.608 & 38.132 & 0.996 & 0.948 \\
& Assim & -34.708 & 38.166 & 0.996 & 0.949 \\
\hline \multirow{2}{*}{ Alkalinity } & Control & -36.384 & 37.849 & 0.986 & 1.097 \\
& Assim & -36.425 & 37.876 & 0.986 & 1.096 \\
\hline$p \mathrm{CO}_{2}$ & Control & 50.425 & 74.995 & 0.221 & 1.185 \\
& Assim & 44.472 & 73.622 & 0.259 & 1.340 \\
\hline
\end{tabular}

Table 3, for both variables there is very little difference between Control and Assim, showing the assimilation to have little impact on the carbon cycle at this location. Assim has a marginally higher bias and RMSE than Control, but this difference is negligible. In each case the model already provides a very good fit to the observations with Control having a correlation of 0.996 and a median percentage error of $-1.653 \%$ for DIC, and a correlation of 0.986 and a median percentage error of $-1.510 \%$ for alkalinity. 
In situ observations of sea surface $p \mathrm{CO}_{2}$ were obtained from the British Oceanographic Data Centre (BODC) as part of the CARBON-OPS project (Hardman-Mountford et al., 2008). Table 3 shows statistics comparing each model run to these observations, which were quality controlled and delivered in NRT from the RRS James Clark Ross, a novel feature of the project. Although the observations have undergone automatic rather than full quality control, a conservative error estimate of $15 \mu \mathrm{atm}$ (N. Hardman-Mountford, personal communication, 2012) is within the model errors shown in Table 3. Both Control and Assim show a poor representation of $p \mathrm{CO}_{2}$, with values too high across most of the ocean. However, compared to the CARBON-OPS observations, Assim shows an improved representation, with lower bias and RMSE, and higher correlation (although a worsened normalised standard deviation). This suggests that the assimilation may be improving the carbon cycle within the model, which would make it more suitable for monitoring air-sea carbon fluxes.

\section{Summary and discussion}

The study presented here aimed to assess the impact of assimilating GlobColour ocean colour data into the FOAMHadOCC coupled physical-biogeochemical model. Daily averaged merged chlorophyll data were quality controlled and assimilated using the analysis correction technique, with the chlorophyll increments used to update all biogeochemical state variables at all depths. The assimilation considerably improved the bias, RMSE and correlation with the GlobColour observations compared to a control run. This improvement was immediate, and sustained over the entire year and in every ocean basin. Errors against independent in situ observations were also reduced, although climatology provided a better representation. The improvement was greatest at the surface, but also occurred at depth. Furthermore, there were consistent changes in other biogeochemical variables, particularly phytoplankton, zooplankton and detritus. The assimilation did not degrade the other model variables, and there was evidence of improvement in some instances, although an overall improvement was not demonstrated. Annual mean surface fields of nitrate, DIC, alkalinity, $p \mathrm{CO}_{2}$ and air-sea $\mathrm{CO}_{2}$ flux were of similar quality compared to climatology in both runs. There were also reduced errors against in situ observations of nitrate and $p \mathrm{CO}_{2}$, but too few data were used to be able to draw broader conclusions about model skill.

The biological assimilation scheme (Hemmings et al., 2008) is designed to be computationally efficient. The average time taken to run FOAM-HadOCC for a day was $306 \mathrm{~s}$ for the control run, and $318 \mathrm{~s}$ for the assimilation run (both of which assimilated physical data). This represents an increased computational cost of $4 \%$, which compares favourably to commonly used techniques, such as the ensemble Kalman filter (Evensen, 1994).

Since June 2009 FOAM-HadOCC has been running daily on a pre-operational basis. This mimics the operational FOAM suite (Storkey et al., 2010). Each day the latest GlobColour merged product is downloaded and processed by the OPS. This is assimilated by FOAM-HadOCC and an analysis and six-day forecast produced. Verification of these forecasts is outside the scope of this paper and will be addressed in future publications.

The NRT GlobColour products are typically available by 14:00 UTC the day after the observations are valid, and the system runs shortly after this time. The availability of these products has been found to be sufficiently reliable for operational purposes, with the products successfully downloaded on approximately $89 \%$ of days over the period $1 \mathrm{Au}-$ gust 2009-31 July 2011. MyOcean implemented availability monitoring in October 2010, and over the following year the GlobColour products were found to be made available on time on $95 \%$ of days. This is comparable to the reliability of remotely sensed SST products provided by the Group for High Resolution Sea Surface Temperature (GHRSST). Donlon et al. (2012) found different GHRSST products to be successfully delivered on 88-98\% of days over a four-year period. On some of the days when the GlobColour products were not successfully downloaded or assimilated, this was due to technical problems inherent in the pre-operational nature of the system. A fully operational system would be more robust and this would not be an issue. On other occasions the products were not made available on time by GlobColour. Reasons for this include outages of the GlobColour servers and delayed transmission of the satellite data by the data providers.

During July 2009, products from FOAM-HadOCC were automatically provided to the GlobColour team on a daily basis via File Transfer Protocol (FTP). These products were images of chlorophyll and primary productivity covering the analysis and each day of the forecast. This successfully demonstrated the full end-to-end capability of the system, using the GlobColour products to automatically provide products for a customer on an operational-style basis.

A number of conclusions and recommendations can be drawn from this work. The assimilation of GlobColour data has been demonstrated to improve the quality of a coupled physical-biogeochemical model, and its use should be promoted in the delivery of both NRT operational-style systems and reanalyses. Observations should continue to be produced in NRT and the sooner after the observation time these are available the better. For example, the current operational FOAM suite runs at 05:00 UTC each day and so, for full use to be made of observations, they need to be available before this time.

Whilst data assimilation has demonstrated the ability to improve the quality of model output, significant focus must still be given to developing the underlying model. As shown 
in Fig. 4, there are large biases which need to be addressed, as these currently prevent the assimilative system from being consistently more accurate than climatology. Some of these biases result from the physical data assimilation, which demonstrably improves the physical variables, but can create spurious mixing which degrades the biogeochemistry. Others result from deficiencies with the biogeochemical model. It is planned to address both these issues as a high priority. Potential improvements to the model could come from better parameterising the growth, mortality and grazing rates of phytoplankton and zooplankton, either through changes to the model equations, or tuning of the current model parameters. A more complex light model could be implemented, in order to explicitly resolve the diurnal cycle, and the same light model used for both the physics and biogeochemistry. The effect of increasing horizontal and vertical resolution could also be investigated, as well as changes to ecosystem model complexity (for instance the inclusion of iron and oxygen).

The multivariate aspect of both this and other chlorophyll assimilation schemes should be a priority for future assimilation development. The scheme presented here has succeeded in maintaining, and in some cases improving, the quality of the other variables. However, greater success could come from the use of data assimilation for simultaneous state and parameter estimation. As well as updating the model variables, giving an improved representation of the current state, the assimilation could also alter tuneable model parameters, thereby changing the model trajectory in order to reduce biases. Furthermore, the assimilation could also be integrated with the assimilation of other biogeochemical variables, such as $p \mathrm{CO}_{2}$. It could also be fully integrated with the physical assimilation, such that temperature and other factors directly influence the chlorophyll increments, and potentially vice versa, ensuring the physics and biogeochemistry are consistent.

This study has made use of merged, daily averaged level three chlorophyll observations. However, it is typically preferred to use level two (Blower et al., 2009) or level three uncollated (GHRSST Science Team, 2010) observations for data assimilation. These do not merge information from different sensors, and contain the exact time of each observation. This allows the observation operator to compare model and observation values at the observed time, rather than an arbitrary time, thus providing a more accurate comparison which accounts for the diurnal cycle. Furthermore, the errors of the different sensors are handled separately, so the error characteristics of each observation should be known more accurately. This is important for both data assimilation and quality control, as well as allowing bias correction schemes to be devised. A future publication will compare the assimilation of the level three merged products to the equivalent level three uncollated products in FOAM-HadOCC, and it is suggested that the routine production of such products would be potentially beneficial for data assimilation. If these were produced in NRT, then they could also be made available with less of a delay than the daily averaged products. However, better use of the merged data could also be made by the data assimilation. For example, the observation operator could compare the daily mean observations to a daily mean model field, or perform the comparison at local noon rather than model noon.

To extend the work presented here, multi-year reanalyses will be performed with and without assimilation, and be used to investigate inter-annual variability. Furthermore, biogeochemical forecasts produced by the system will be assessed, to investigate whether the assimilation allows forecasts to be produced that are more skilful than persistence or climatology.

\section{Appendix A}

Table A1. List of parameters used in the HadOCC model.

\begin{tabular}{|c|c|}
\hline Parameter & Value \\
\hline $\mathrm{C}: \mathrm{N}$ ratio for phytoplankton & 6.625 \\
\hline $\mathrm{C}: \mathrm{N}$ ratio for zooplankton & 5.625 \\
\hline $\mathrm{C}: \mathrm{N}$ ratio for detritus & 7.5 \\
\hline Maximum photosynthetic rate & $1.5 \mathrm{day}^{-1}$ \\
\hline Initial slope of photosynthesis-irradiance curve & $0.055\left(\mathrm{~W} \mathrm{~m}^{-2}\right)^{-1} \mathrm{day}^{-1}$ \\
\hline $\begin{array}{l}\text { Half-saturation concentration for nutrient up- } \\
\text { take }\end{array}$ & $0.1 \mathrm{mmol} \mathrm{N} \mathrm{m}^{-3}$ \\
\hline Phytoplankton specific respiration & 0.05 day $^{-1}$ \\
\hline $\begin{array}{l}\text { Concentration-dependent phytoplankton spe- } \\
\text { cific mortality }\end{array}$ & $\begin{array}{l}0.05 \text { day }^{-1} \\
\left(\mathrm{mmol} \mathrm{N} \mathrm{m}^{-3}\right)\end{array}$ \\
\hline Maximum grazing rate & 0.8 day $^{-1}$ \\
\hline Half-saturation concentration for grazing & $0.5 \mathrm{mmol} \mathrm{N} \mathrm{m}^{-3}$ \\
\hline Grazing threshold & $0.01 \mathrm{mmol} \mathrm{N} \mathrm{m}^{-3}$ day $^{-1}$ \\
\hline Assimilation efficiency for zooplankton & 0.9 \\
\hline Assimilation efficiency for detritus & 0.65 \\
\hline Base zooplankton specific mortality & 0.05 day $^{-1}$ \\
\hline $\begin{array}{l}\text { Concentration-dependent zooplankton specific } \\
\text { mortality }\end{array}$ & 0.3 day $^{-1}$ \\
\hline Remineralisation rate & $\begin{array}{l}0.1 \text { day }^{-1} \\
(\text { depth }<100 \mathrm{~m}) \\
8.58 \text { depth }^{-1} \text { day }^{-1} \\
(\text { depth }>100 \mathrm{~m})\end{array}$ \\
\hline Detrital sinking velocity & $10.0 \mathrm{~m} \mathrm{day}^{-1}$ \\
\hline $\begin{array}{l}\text { Carbonate precipitated per unit primary produc- } \\
\text { tion }\end{array}$ & 0.013 \\
\hline Minimum carbon to chlorophyll ratio & 20.0 \\
\hline Maximum carbon to chlorophyll ratio & 200.0 \\
\hline Fraction of grazed material ingested & 0.77 \\
\hline
\end{tabular}




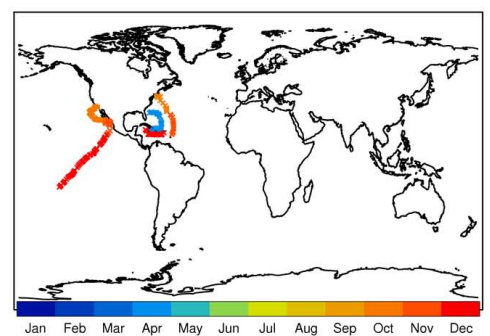

a) SeaBASS chlorophyll (surface)

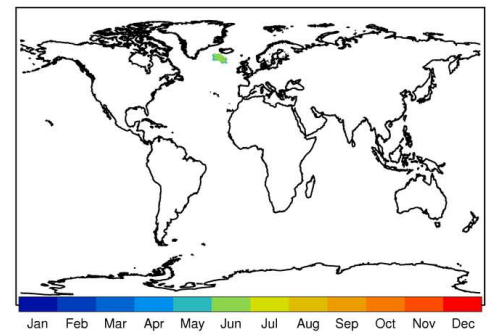

c) SeaBASS nitrate

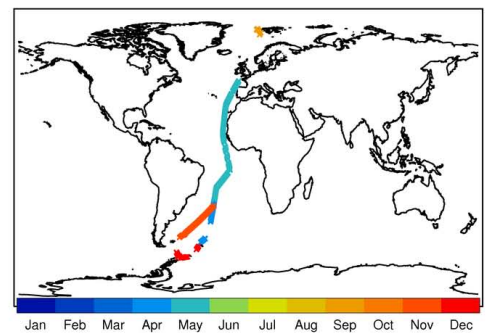

e) $\mathrm{CARBON}-\mathrm{OPS} \mathrm{pCO} 2$

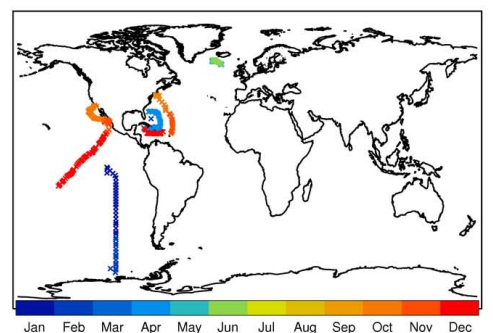

b) SeaBASS chlorophyll (all depths)

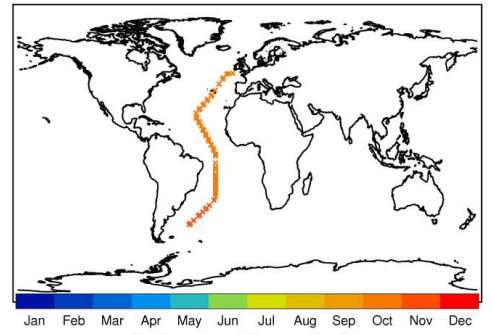

d) AMT chlorophyll

Fig. A1. Locations and months of in situ observations used from SeaBASS, CARBON-OPS and AMT.

Acknowledgements. The work presented here was funded by the ESA DUE GlobColour program and ARGANS under contract number ARG/001-001/0812_CCN_METOFFICE with continuation support from the EC FP7/2007-2013 program under grant agreement no. 218812 (MyOcean). The authors would also like to thank ESA for funding the Climate Modelling User Group (Contract 4000100222/10/I-AM) as part of its Climate Change Initiative, through which a part of the assessment presented here was conducted. The SeaWiFS and MODIS-Aqua data were available thanks to NASA and OrbView while ESA provided the MERIS data. Through the use of AMT data, this study was supported by the UK Natural Environment Research Council through the UK marine research institutes' strategic research programme Oceans 2025 awarded to Plymouth Marine Laboratory and the National Oceanography Centre, Southampton; this is contribution number 212 of the AMT programme. $p \mathrm{CO}_{2}$ data were supplied by the British Oceanographic Data Centre and collected by Plymouth Marine Laboratory under the UK Natural Environment Research Council Knowledge Transfer Programme CARBON-OPS NE/E002021/1; the authors would like to thank Nick Hardman-Mountford and Gwen Moncoiffé for their work providing the data. HOT ALOHA data were obtained from http://hahana.soest.hawaii.edu/hot/hot-dogs/bextraction.html. For contributing data to SeaBASS the authors thank Frank Muller-
Karger and the team at the Institute for Marine Remote Sensing, University of South Florida, and Ramon Varela and Yrene Astor and their team at the Fundacion La Salle de Ciencias Naturales de Venezuela, for the bio-optical and other oceanographic data collected at the CARIACO Ocean Time Series; E. D'Asaro, I. Cetinic, K. Fennel, C. M. Lee, and M. J. Perry for collecting data as part of the North Atlantic Bloom Experiment 2008, with support from US National Science Foundation (OCE-0628107 and 462 OCE-0628379) and NASA (NNX-08AL92G); the Bermuda Bio-Optics Project (BBOP); and the SEA Semester program run by Sea Education Association. The authors would also like to thank Ian Totterdell for help with HadOCC; John Hemmings for discussions about the data assimilation scheme and for generating Fig. 1; Mike Bell for comments on the draft manuscript; and Anna Teruzzi and two anonymous reviewers for their comments in Ocean Science Discussions.

Edited by: P. Brasseur 


\section{References}

Allen, J. I., Eknes, M., and Evensen, G.: An Ensemble Kalman Filter with a complex marine ecosystem model: hindcasting phytoplankton in the Cretan Sea, Ann. Geophys., 21, 399-411, doi:10.5194/angeo-21-399-2003, 2003.

Anderson, L. A., Robinson, A. R., and Lozano, C. J.: Physical and biological modeling in the Gulf Stream region - Part 1: Data assimilation methodology, Deep-Sea Res. Pt. I, 47, 1787-1827, 2000.

Anderson, T. R.: A spectrally averaged model of light penetration and photosynthesis, Limnol. Oceanogr., 38, 1403-1419, 1993.

Bailey, S. W. and Werdell, P. J.: A multi-sensor approach for the on-orbit validation of ocean color satellite data products, Remote Sens. Environ., 102, 12-23, 2006.

Barnes, C., Irigoien, X., De Oliveira, J. A. A., Maxwell, D., and Jennings, S.: Predicting marine phytoplankton community size structure from empirical relationships with remotely sensed variables, J. Plankton Res., 33, 13-24, 2011.

Berger, H., Langland, R., Velden, C. S., Reynolds, C. A., and Pauley, P. M.: Impact of enhanced satellite-derived atmospheric motion vector observations on numerical tropical cyclone track forecasts in the Western North Pacific during TPARC/TCS-08, J. Appl. Meteorol. Clim., 50, 2309-2318, 2011.

Berx, B., Dickey-Collas, M., Skogen, M. D., De Roeck, Y.-H., Klein, H., Barciela, R., Forster, R. M., Dombrowsky, E., Huret, M., Payne, M., Sagarminaga, Y., and Schrum, C: Does operational oceanography address the needs of fisheries and applied environmental scientists?, Oceanography, 24, 166-171, 2011.

Beşiktepe, Ş. T., Lermusiaux, P. F. J., and Robinson, A. R.: Coupled physical and biogeochemical data-driven simulations of Massachusetts Bay in late summer: real-time and postcruise data assimilation, J. Marine Syst., 40, 171-212, 2003.

Bloom, S. C., Takacs, L. L., da Silva, A. M., and Ledvina, D.: Data assimilation using incremental analysis updates, Mon. Weather Rev., 124, 1256-1271, 1996.

Blower, J. D., Blanc, F., Clancy, M., Cornillon, P., Donlon, C., Hacker, P., Haines, K., Hankin, S. C., Loubrieu, T., Pouliquen, S., Price, M., Pugh, T. F., and Srinivasan, A.: Serving GODAE data and products to the ocean community, Oceanography, 22, 70-79, 2009.

Bocquet, M., Pires, C. A., and Wu, L.: Beyond Gaussian statistical modeling in geophysical data assimilation, Mon. Weather Rev., 138, 2997-3023, 2010.

Brankart, J.-M., Testut, C.-E., Béal, D., Doron, M., Fontana, C., Meinvielle, M., Brasseur, P., and Verron, J.: Towards an improved description of ocean uncertainties: effect of local anamorphic transformations on spatial correlations, Ocean Sci., 8, 121-142, doi:10.5194/os-8-121-2012, 2012.

Brasseur, P., Gruber, N., Barciela, R., Brander, K., Doron, M., El Moussaoui, A., Hobday, A. J., Huret, M., Kremeur, A. S., Lehodey, P., Matear, R., Moulin, C., Murtugudde, R., Senina, I., and Svendsen, E.: Integrating biogeochemistry and ecology into ocean data assimilation systems, Oceanography, 22, 206$215,2009$.

Campbell, J. W.: The lognormal distribution as a model for biooptical variability in the sea, J. Geophys. Res., 100, 1323713254, 1995.

Carmillet, V., Brankart, J.-M., Brasseur, P., Drange, H., Evensen, G., and Verron, J.: A singular evolutive extended Kalman filter to assimilate ocean color data in a coupled physical-biochemical model of the North Atlantic ocean, Ocean Model., 3, 167-192, 2001.

Ciavatta, S., Torres, R., Saux-Picart, S., and Allen, J. I.: Can ocean color assimilation improve biogeochemical hindcasts in shelf seas?, J. Geophys. Res., 116, C12043, doi:10.1029/2011JC007219, 2011.

Cox, P. M., Betts, R. A., Jones, C. D., Spall, S. A., and Totterdell, I. J.: Acceleration of global warming due to carbon-cycle feedbacks in a coupled climate model, Nature, 408, 184-187, 2000.

Cummings, J., Bertino, L., Brasseur, P., Fukumori, I., Kamachi, M., Martin, M. J., Mogensen, K., Oke, P., Testut, C. E., Verron, J., and Weaver, A.: Ocean data assimilation systems for GODAE, Oceanography, 22, 96-109, 2009.

Donlon, C. J., Martin, M., Stark, J., Roberts-Jones, J., Fiedler, E., and Wimmer, W.: The Operational Sea Surface Temperature and Sea Ice Analysis (OSTIA) system, Remote Sens. Environ., 116, 140-158, 2012.

Eknes, M. and Evensen, G.: An ensemble Kalman filter with a 1-D marine ecosystem model, J. Marine Syst., 36, 75-100, 2002.

El Moussaoui, A., Perruche, C., Greiner, E., Ethé, C., and Gehlen, M.: Integration of biogeochemistry into Mercator Ocean systems, Mercator Ocean Newsletter \#40, January 2011, available at: http://www.mercator-ocean.fr/fre/actualitesagenda/newsletter/newsletter-Newsletter-40-Les-modelesnumeriques-des-ecosystemes-MyOcean (last access: December 2011), 2011.

Eppley, R. W.: Temperature and phytoplankton growth in the sea, Fish. B.-NOAA, 70, 1063-1085, 1972.

Evensen, G.: Sequential data assimilation with a nonlinear quasigeostrophic model using Monte Carlo methods to forecast error statistics, J. Geophys. Res., 99, 10143-10162, 1994.

Fanton d'Andon, O. H., Antoine, D., Mangin, A., Maritorena, S., Durand, D., Pradhan, Y., Lavender, S., Morel, A., Demaria, J., and Barrot, G.: Ocean colour sensors characterisation and expected error estimates of ocean colour merged products from GlobColour, Ocean Optics XIX, Barga, Italy, 6-10 October 2008, 51 pp., 2008.

Fontana, C., Grenz, C., and Pinazo, C.: Sequential assimilation of a year-long time-series of SeaWiFS chlorophyll data into a 3-D biogeochemical model on the French Mediterranean coast, Cont. Shelf Res., 30, 1761-1771, 2010.

Garcia, H. E., Locarnini, R. A., Boyer, T. P., and Antonov, J. I.: World Ocean Atlas 2005, Vol. 4: Nutrients (phosphate, nitrate, silicate), edited by: Levitus, S., NOAA Atlas NESDIS 64, US Government Printing Office, Washington, DC, 396 pp., 2006.

Garcia, H. E., Locarnini, R. A., Boyer, T. P., Antonov, J. I., Zweng, M. M., Baranova, O. K., and Johnson, D. R.: World Ocean Atlas 2009, Vol. 4: Nutrients (phosphate, nitrate, and silicate), edited by: Levitus, S., NOAA Atlas NESDIS 71, US Government Printing Office, Washington, DC, 398 pp., 2010.

Geider, R. J., MacIntyre, H. L., and Kana, T. M.: A dynamic model of photoadaptation in phytoplankton, Limnol. Oceanogr., 41, 115,1996

Geider, R. J., MacIntyre, H. L., and Kana, T. M.: Dynamic model of phytoplankton growth and acclimation: responses of the balanced growth rate and the chlorophyll $a$ : carbon ratio to light, nutrient-limitation and temperature, Mar. Ecol.-Prog. Ser., 148, 187-200, 1997. 
GHRSST Science Team: The Recommended GHRSST Data Specification (GDS) 2.0, document revision 4, available from the GHRSST International Project Office, 2011, 123 pp., 2010.

Gregg, W. W.: Assimilation of SeaWiFS ocean chlorophyll data into a three-dimensional global ocean model, J. Marine Syst., 69, 205-225, 2008.

Gregg, W. W. and Casey, N. W.: Improving the consistency of ocean color data: A step toward climate data records, Geophys. Res. Lett., 37, L04605, doi:10.1029/2009GL041893, 2010.

Gregg, W. W., Friedrichs, M. A. M., Robinson, A. R., Rose, K. A., Schlitzer, R., Thompson, K. R., and Doney, S. C.: Skill assessment in ocean biological data assimilation, J. Marine Syst., 76, 16-33, 2009.

Hardman-Mountford, N. J., Moore, G. F., Bakker, D. C. E., Watson, A. J., Schuster, U., Barciela, R., Hines, A., Moncoiffé, G., Brown, J., Dye, S., Blackford, J., Somerfield, P., Holt, J., Hydes, D. J., and Aiken, J.: An operational monitoring system to provide indicators of $\mathrm{CO}_{2}$-related variables in the ocean, ICES J. Mar. Sci., 65, 1498-1503, 2008.

Hemmings, J. C. P., Srokosz, M. A., Challenor, P., and Fasham, M. J. R.: Split-domain calibration of an ecosystem model using satellite ocean colour data, J. Marine Syst., 50, 141-179, 2004.

Hemmings, J. C. P., Barciela, R. M., and Bell, M. J.: Ocean color data assimilation with material conservation for improving model estimates of air-sea $\mathrm{CO}_{2}$ flux, J. Mar. Res., 66, 87-126, 2008.

Hollingsworth, A. and Lönnberg, P.: The statistical structure of short-range forecast errors as determined from radiosonde data - Part I: The wind field, Tellus A, 38, 111-136, 1986.

Hooker, S. B., Esaias, W. E., Feldman, G. C., Gregg, W. W., and McClain, C. R.: An overview of SeaWiFS and ocean color, NASA Tech. Memo., Vol. 104566, National Aeronautics and Space Administration, Goddard Space Flight Center, Greenbelt, MD, 1992.

Hoteit, I., Triantafyllou, G., Petihakis, G., and Allen, J. I.: A singular evolutive extended Kalman filter to assimilate real in situ data in a 1-D marine ecosystem model, Ann. Geophys., 21, 389-397, doi:10.5194/angeo-21-389-2003, 2003.

Hoteit, I., Triantafyllou, G., and Petihakis, G.: Efficient data assimilation into a complex, 3-D physical-biogeochemical model using partially-local Kalman filters, Ann. Geophys., 23, 3171-3185, doi:10.5194/angeo-23-3171-2005, 2005.

Ingleby, B. and Huddleston, M.: Quality control of ocean temperature and salinity profiles - historical and real-time data, J. Marine Syst., 65, 158-175, 2007.

Ingleby, N. B. and Lorenc, A. C.: Bayesian quality control using multivariate normal distributions, Q. J. Roy. Meteor. Soc., 119, 1195-1225, 1993.

Ishizaka, J.: Coupling of Coastal Zone Color Scanner data to a physical-biological model of the southeastern United-States continental-shelf ecosystem - Part 3: Nutrient and phytoplankton fluxes and CZCS data assimilation, J. Geophys. Res., 95, 2020120212, 1990.

Kalnay, E.: Atmospheric modeling, data assimilation and predictability, Cambridge University Press, Cambridge, 2003.

Key, R. M., Kozyr, A., Sabine, C. L., Lee, K., Wanninkhof, R., Bullister, J. L., Feely, R. A., Millero, F. J., Mordy, C., and Peng, T.-H.: A global ocean carbon climatology: Results from Global Data Analysis Project (GLODAP), Global Biogeochem. Cy., 18,
GB4031, doi:10.1029/2004GB002247, 2004.

Le Traon, P.-Y., Larnicol, G., Guinehut, S., Pouliquen, S., Bentamy, A., Roemmich, D., Donlon, C., Roquet, H., Jacobs, G., Griffin, D., Bonjean, F., Hoepffner, N., and Breivik, L.-A.: Data assembly and processing for operational oceanography: 10 years of achievements, Oceanography, 22, 56-69, 2009.

Lévy, M., Estublier, A., and Madec, G.: Choice of an advection scheme for biogeochemical models, Geophys. Res. Lett., 28, 3725-3728, 2001.

Lorenc, A. C., Bell, R. S., and MacPherson, B.: The Meteorological Office analysis correction data assimilation scheme, Q. J. Roy. Meteor. Soc., 117, 59-89, 1991.

Losa, S. N., Kivman, G. A., Schröter, J., and Wenzel, M.: Sequential weak constraint parameter estimation in an ecosystem model, J. Marine Syst., 43, 31-49, 2003.

Madec, G.: NEMO ocean engine, Note du Pole de modélisation, Institut Pierre-Simon Laplace (IPSL), France, No. 27 ISSN, 12881619, 2008.

Maritorena, S., Fanton d'Andon, O. H., Mangin, A., and Siegel, D. A.: Merged satellite ocean color data products using a biooptical model: Characteristics, benefits and issues, Remote Sens. Environ., 114, 1791-1804, 2010.

Martin, M. J., Hines, A., and Bell, M. J.: Data assimilation in the FOAM operational short-range ocean forecasting system: a description of the scheme and its impact, Q. J. Roy. Meteor. Soc., 133, 981-995, 2007.

Matear, R. J.: Parameter optimization and analysis of ecosystem models using simulated annealing: A case study at Station P, J. Mar. Res., 53, 571-607, 1995.

Morel, A. and Prieur, L.: Analysis of variations in ocean color, Limnol. Oceanogr., 22, 709-722, 1977.

Natvik, L.-J. and Evensen, G.: Assimilation of ocean colour data into a biochemical model of the North Atlantic - Part 1: Data assimilation experiments, J. Marine Syst., 40-41, 127-153, 2003.

Nerger, L. and Gregg, W. W.: Assimilation of SeaWiFS data into a global ocean-biogeochemical model using a local SEIK filter, J. Marine Syst., 68, 237-254, 2007.

Nerger, L. and Gregg, W. W.: Improving assimilation of SeaWiFS data by the application of bias correction with a local SEIK filter, J. Marine Syst., 73, 87-102, 2008.

O'Brien, T.: Copepod: a global plankton database, US Dep. Commerce, NOAA Tech. Memo. NMFS-F/SPO-73, 136 pp., 2005.

O’Reilly, J. E., Maritorena, S., Mitchell, B. G., Siegel, D. A., Carder, K. L., Garver, S. A., Kahru, M., and McClain, C. R.: Ocean color chlorophyll algorithms for SeaWiFS, J. Geophys. Res., 103, 24937-24953, 1998.

Oke, P. R. and Sakov, P.: Representation error of oceanic observations for data assimilation, J. Atmos. Ocean. Tech., 25, 1004 1017, 2008.

Ourmières, Y., Brasseur, P., Lévy, M., Brankart, J.-M., and Verron, J.: On the key role of nutrient data to constrain a coupled physical-biogeochemical assimilative model of the North Atlantic Ocean, J. Marine Syst., 75, 100-115, 2009.

Palmer, J. R. and Totterdell, I. J.: Production and export in a global ocean ecosystem model, Deep-Sea Res. Pt. I, 48, 1169-1198, 2001.

Parrish, D. F. and Derber, J. C.: The National Meteorological Center's spectral statistical-interpolation analysis system, Mon. Weather Rev., 120, 1747-1763, 1992. 
Popova, E. E., Lozano, C. J., Srokosz, M. A., Fasham, M. J. R., Haley, P. J., and Robinson, A. R.: Coupled 3-D physical and biological modelling of the mesoscale variability observed in North-East Atlantic in Spring 1997: biological processes, DeepSea Res. Pt. I, 49, 1741-1768, 2002.

Purser, R. J., Parrish, D. F., and Masutani, M.: Meteorological observational data compression: An alternative to conventional "super-obbing", NCEP Office Note 430, available at: http://www.ncep.noaa.gov/officenotes/ NOAA-NPM-NCEPON-0006/01408B82.pdf (last access: December 2011), 2000.

Raick, C., Alvera-Azcarate, A., Barth, A., Brankart, J. M., Soetaert, K., and Grégoire, M.: Application of a SEEK filter to a 1-D biogeochemical model of the Ligurian Sea: twin experiments and real in-situ data assimilation, J. Marine Syst., 65, 561-583, 2007.

Samuelsen, A. and Bertino, L.: Arctic Ocean ecosystem modeling in MyOcean, Mercator Ocean Newsletter \#40, January 2011, available at: http://www.mercator-ocean.fr/fre/actualitesagenda/newsletter/newsletter-Newsletter-40-Les-modelesnumeriques-des-ecosystemes-MyOcean (last access: December 2011), 2011.

Simon, E. and Bertino, L.: Gaussian anamorphosis extension of the DEnKF for combined state parameter estimation: Application to a 1-D ocean ecosystem model, J. Marine Syst., 89, 1-18, 2012.

Storkey, D., Blockley, E. W., Furner, R., Guiavarc'h, C., Lea, D., Martin, M. J., Barciela, R. M., Hines, A., Hyder, P., and Siddorn, J. R.: Forecasting the ocean state using NEMO: The new FOAM system, J. Operational Oceanogr., 3, 3-15, 2010.

Takahashi, T., Sutherland, S. C., Wanninkhof, R., Sweeney, C., Feely, R. A., Chipman, D. W., Hales, B., Friederich, G., Chavez, F., Sabine, C., Watson, A., Bakker, D. C. E., Schuster, U., Metzl, N., Yoshikawa-Inoue, H., Ishii, M., Midorikawa, T., Nojiri, Y., Körtzinger, A., Steinhoff, T., Hoppema, M., Olafsson, J., Arnarson, T. S., Tilbrook, B., Johannessen, T., Olsen, A., Bellerby, R., Wong, C. S., Delille, B., Bates, N. R., and de Baar, H. J. W.: Climatological mean and decadal changes in surface ocean $p \mathrm{CO}_{2}$, and net sea-air $\mathrm{CO}_{2}$ flux over the global oceans, Deep-Sea Res. Pt. II, 56, 554-577, 2009.
Talagrand, O.: Assimilation of observations, an introduction, J. Meteorol. Soc. Jpn., 75, 191-209, 1997.

Taylor, K. E.: Summarizing multiple aspects of model performance in a single diagram, J. Geophys. Res., 106, 7183-7192, 2001.

Teruzzi, A., Salon, S., Bolzon, G., Lazzari, P., Campagna, S., Ficarelli, F., Solidoro, C., and Crise, A.: Operational forecasts of the biogeochemical state of the Mediterranean Sea, Mercator Ocean Newsletter \#40, January 2011, available at: http://www.mercator-ocean.fr/fre/actualitesagenda/newsletter/newsletter-Newsletter-40-Les-modelesnumeriques-des-ecosystemes-MyOcean (last access: December 2011), 2011.

Timmermann, R., Goosse, H., Madec, G., Fichefet, T., Ethe, C., and Dulière, V.: On the representation of high latitude processes in the ORCA-LIM global coupled sea ice-ocean model, Ocean Model., 8, 175-201, 2005.

Torres, R., Allen, J. I., and Figueiras, F. G.: Sequential data assimilation in an upwelling influenced estuary, J. Marine Syst., 60, 317-329, 2006.

Totterdell, I. J. and Halloran, P.: Diat-HadOCC: an ocean biogeochemical model for climate studies, in preparation, 2012.

Triantafyllou, G., Hoteit, I., and Petihakis, G.: A singular evolutive interpolated Kalman filter for efficient data assimilation in a 3D complex physical-biogeochemical model of the Cretan Sea, J. Marine Syst., 40, 213-231, 2003.

Werdell, P. J., Bailey, S. W., Fargion, G. S., Pietras, C., Knobelspiesse, K. D., Feldman, G. C., and McClain, C. R.: Unique data repository facilitates ocean color satellite validation, EOS T. Am. Geophys. Un., 84, 377-392, 2003.

While, J., Totterdell, I. J., and Martin, M. J.: Assimilation of $p \mathrm{CO}_{2}$ data into a global coupled physical-biogeochemical ocean model, J. Geophys. Res., 117, C03037, doi:10.1029/2010JC006815, 2012. 